Federal Reserve Bank of Dallas

Globalization and Monetary Policy Institute

Working Paper No. 303

https://www.dallasfed.org/ /media/documents/institute/wpapers/2017/0303.pdf

\title{
The Impact of Global Uncertainty on the Global Economy, and Large Developed and Developing Economies*
}

\author{
Wensheng Kang \\ Kent State University \\ Ronald A. Ratti \\ Western Sydney University \\ Joaquin Vespignani \\ University of Tasmania
}

January 2017

\begin{abstract}
Global uncertainty shocks are associated with a sharp decline in global inflation, global growth and in the global interest rate. Over 1981 to 2014 global financial uncertainty forecasts $18.26 \%$ and $14.95 \%$ of the variation in global growth and global inflation respectively. Global uncertainty shocks have more protracted, statistically significant and substantial effects on global growth, inflation and interest rate than U.S. uncertainty shocks. U.S. uncertainty lags global uncertainty by one month. When controlling for domestic uncertainty, the decline in output following a rise in global uncertainty is statistically significant in each country, with the exception of the decline for China. The effects for the U.S. and for China are also relatively small. For most economies, a positive shock to global uncertainty has a depressing effect on prices and official interest rates. Exceptions are Brazil, Mexico and Russia, economies with large capital outflows during financial crises. Decomposition of global uncertainty shocks shows that global financial uncertainty shocks are more important than non-financial shocks.
\end{abstract}

JEL codes: D80, E44, E66, F62, G10

\footnotetext{
* Wensheng Kang, Kent State University, Kent, OH 44242. 330-308-7414. wkang3@kent.edu. Ronald A. Ratti, School of Business, University of Western Sydney, Australia. 2-9685-9346. r.ratti@westernsydney.edu.au. Joaquin L. Vespignani, University of Tasmania, Tasmanian School of Business and Economics, Australia.61-3-62262825. joaquin.vespignani@utas.edu.au. We would like to thank: Scott Baker, Nicholas Bloom, Hilde Bjornland, Efrem Castelnuovo, Mardi Dungey, Valerie Grossman, Enrique Martinez-Garcia and Francesco Ravazzolo, and our discussant James Hansen for useful comments on the early versions: "Global Uncertainty" and "Global Uncertainty and the Global Economy: Decomposing the Effects of Financial and Non-financial Shocks" and members of the Melbourne Institute, Centre for Applied Macro and Petroleum Economics, Norges Bank and BI Norwegian Business School and seminar participants at CAMP-Melbourne Institute Applied Macroeconometrics Workshop (2015). The views in this paper are those of the authors and do not necessarily reflect the views of the Federal Reserve Bank of Dallas or the Federal Reserve System.
} 


\section{The Impact of Global Uncertainty on the Global Economy, and Large Developed and Developing Economies}

\section{Introduction}

The adverse impact of uncertainty on economic activity has received renewed interest following the influential study by Bloom (2009). These investigations have analysed the effect of country level uncertainty (usually U.S. uncertainty) on economic variables within a country, or alternatively, considered the impact of a measure of global uncertainty on economic variables within a country. ${ }^{1}$ The rapid and accelerating process of financial globalization and new technologies prompt the question as to whether it is useful for economic uncertainty to be addressed as a global phenomenon, whose effects are examined for the global economy, as well as either a country-specific occurrence or a global occurrence examined for country specific effects.

In this study we aim to answer the questions: How does global uncertainty affect the global economy? Do global uncertainty shocks have different effects than U.S. uncertainty shocks on the global economy? How do large developed and developing economies respond to global uncertainty shocks? Does the source of uncertainty shock matter for the global economy? To answer these questions, we developed an index of global uncertainty using the first principal component of the stock market volatility of the largest 15 economies. ${ }^{2}$ We also evaluate the impact of global uncertainty on global interest rate, inflation and industrial production using the new global database from Global Economic Indicators (DGEI), Federal Reserve Bank of Dallas. ${ }^{3}$

\footnotetext{
${ }^{1}$ See for example: Baker et al (2015) Bloom (2009), Gilchrist et al. (2010), Knotek and Khan (2011), Fernández-Villaverde et al. (2011), Bekaert et al. (2013), Bachmann et al. (2013), Leduc and Liu (2015), Mumtaz and Theodoridis (2014), and Jurado et al. (2015).

${ }^{2}$ Note that Bloom et al. (2007) show that share-return volatility is significantly correlated with alternative measures of uncertainty proxies.

${ }^{3}$ The methodology underlying the Global Economic Indicators (DGEI) database is provided in Grossman et al. (2014).
} 
The empirical literature on economic uncertainty has generally focused on the volatility of stock market returns and/or firm profitability as providing a measure of uncertain environments within which decisions are made. ${ }^{4}$ High uncertainty causes firms to postpone investment and hiring and consumers to delay important purchases with unfavourable consequences for economic growth. In a major paper, Bloom (2009) emphasizes the negative impact of uncertainty on employment and output for the U.S. after World War II. In his work, Bloom develops an uncertainty index based on firm stock return and/or firm profit growth.

An alternative measure of uncertainty based on spreads between low-rated and highly rated corporate bonds are discussed by a number of authors, including contributions by Favero (2009), Arellano et al. (2010) and Gilchrist et al. (2010). Bredin and Fountas (2009) utilize a general bivariate GARCH-M model to generate the macroeconomic uncertainty associated with output growth and inflation in EU countries. More recently, Jurado et al. (2015) argue that stock market volatility may not be closely linked to "true" economic uncertainty, and propose new time series measures of macroeconomic uncertainty. These time series based indicators are built with U.S. macroeconomic data and are identified as the unforecastable component of the macroeconomic series. Rossi and Sekhposyan (2015) develop a more general approach to describe macroeconomic uncertainty. Their macroeconomic index is based on assessing the likelihood of the realized forecast error of macroeconomic variables. Charemza et al. (2015) suggest a new measure of inflation forecast uncertainty that accounts for possible inter-country dependence.

Berger and Herz (2014) measure global uncertainty as the conditional variances of global factors in inflation and output growth in a bivariate dynamic factor model with GARCH errors for the nine industrialized countries; Canada, France, Germany, Italy, Japan, Netherlands, Spain, United Kingdom, and the United States. Delrio (2016) takes the spread

\footnotetext{
${ }^{4}$ An important thread in the literature is that uncertainty faced by the individual firm is embodied in its own stock price volatility (Leahy and Whited (1996), Bloom (2009), Bloom et al. (2007) and Baum et al. (2010)), among others.
} 
between each country's interbank rate and the federal funds rate as a measure of relative riskiness. This variable is then interacted with global uncertainty given by the realized volatility of daily MSCI World Index returns over calendar quarters. Hirata et al. (2012) find that global house prices are synchronized and that global uncertainty shocks seem to be important in explaining fluctuations in global house prices. As in Bloom (2009), uncertainty is given by the volatility of daily equity prices of the G-7. Ozturk and Sheng (2016) construct a monthly measure of global uncertainty as the PPP-weighted average of the country-specific uncertainties for a dataset of forecast data for 46 advanced and emerging market economies.

Leduc and Liu (2015) examine the effects of uncertainty, measured by Michigan Survey results on the fraction of respondents reporting that "uncertain future" make it a bad time to buy cars or durable goods over the next 12 months, on the U.S. unemployment rate. Mumtaz and Theodoridis (2014) estimate the impact of U.S. GDP growth volatility shocks on the UK in a structural VAR model with time-varying volatility.

Our measure of global uncertainty captures important political, war, financial and economic events over the period 1981 to 2014. Global uncertainty shocks are less frequent than those observed in data on the U.S. economy. Global uncertainty shocks are associated with a sharp decline in global interest rate, global inflation and global industrial production. The maximum decline of global inflation and industrial production occurs six months after a global uncertainty shock, while the maximum decline in global interest rate occurs 16 months after a global uncertainty shock.

Our decomposition of global uncertainty shocks shows that global financial uncertainty shocks are more important than non-financial shocks. Over 1981 to 2014 global financial uncertainty forecasts $18.26 \%$ and $14.95 \%$ of the variation in global growth and global inflation respectively. In contrast, the non-financial uncertainty forecasts only $7.75 \%$ and $2.15 \%$ of the variation in global growth and global inflation, respectively. The effects of 
U.S. uncertainty on global output, inflation and official interest rate are smaller and less statistically significant than the effects of global uncertainty. Measures of U.S. uncertainty and global uncertainty are not substitutable and global uncertainty leads U.S. uncertainty by one month. Output declines in each country with a rise in global uncertainty even controlling for domestic uncertainty, with relatively small effects for the outputs of China and the U.S. Inflation and the official interest decline with positive shocks to global uncertainty, with results for Brazil, Mexico and Russia being exceptions.

This paper proceeds as follows. An index of global uncertainty is constructed in Section 2. The effect of global uncertainty on the global economy is modelled in Section 3. In Section 4 preliminary results are examined with a FAVAR model. Section 5 compares the differences between the U.S. and global uncertainty shocks. Section 6 examines the effects of global uncertainty decomposed by financial and non-financial origin. The effect of global uncertainty on individual major economies when controlling for local uncertainty is evaluated in section 7. Section 8 provides robustness analysis. Section 9 concludes.

\section{An index of global uncertainty}

\subsection{Methodology}

Empirical literature on economic uncertainty has utilized the variability of stock market returns and firm profitability to provide a measure of uncertainty that can influence economic and financial variables. In this study we build on this methodology by constructing a global uncertainty index given by the first principal component of stock market volatility of the largest 15 economies. ${ }^{5}$ It provides a forward-looking indicator that is implicitly weighted in accordance with the impact of different sources of uncertainty across major countries in the world on equity value.

\footnotetext{
${ }^{5}$ Note that this first principal component accounts for around $40 \%$ of the data variation.
} 
Let $R_{c, t}$ be the difference of the natural $\log$ of the stock market index of country $c$ :

$$
R_{c, t}=\ln \frac{S_{c t}}{S_{c t-1}}
$$

where $s_{c t}$ denotes the average monthly stock price for a given country $c$ at time $t$, with $t=1,2 \ldots, T$. Let

$$
V_{c t}=\left(R_{c, t}-\bar{R}_{c, t}\right)^{2},
$$

where $V_{c t}$ is the stock market volatility of country $c$ at time $t, \bar{R}_{c, t}$ is the sample average of $R_{c, t}$. The stock market volatility index is then estimated for the largest 15 economies in 2013 according to the gross domestic product (based on purchase power parity). The countries are Australia, Brazil, Canada, China, Germany, France, India, Italy, Japan, Mexico, Russia, South Korea, South Africa, the United Kingdom (U.K) and the United Sates (U.S). ${ }^{6}$

Given a data matrix with $V_{c t}$ for the 15 largest economies and $n$ samples, we first center on the mean of $V_{c t}$. The first principal component for the global uncertainty index $\left(G U_{t}\right)$ is given by the linear combination of all 15 volatility indices; $V_{\text {Australia }, t}, V_{\text {Brazil }, t}, \ldots ., V_{U S, t}$, Formally:

$$
G U_{t}=a_{1} V_{\text {Australia }, t}+a_{2} V_{\text {Brazil }, t}+\cdots+a_{15} V_{U S, t} .
$$

$G U_{t}$ is calculated such that it accounts for the greatest possible variance in the data set. The weights $\left(a_{i}\right)$ are the elements of an eigenvector with unit length and standardised by the restriction: $a_{1}^{2}+a_{2}^{2}+\cdots+a_{15}^{2}=1$. Data definition, source and period availability is reported in Table A1. ${ }^{7}$

\subsection{Global and the U.S. uncertainty indices.}

\footnotetext{
${ }^{6}$ Note that we attempt to estimate this index for G20 economies. However, data for Indonesia, Iran, Thailand Nigeria and Poland were not available for the full sample period.

${ }^{7}$ Note that data on the stock market is not available for all countries from 1981. The index is constructed with data on the countries for which data are available. A shortcoming of this approach is that for the earlier period, missing data is more apparent for developing countries. Nevertheless, we argue that this is not necessarily a problem, given that in the first part of the sample (1980-1995) the relative weight of developed economies in the global economy is more important than in the more recent period (following China's unprecedented growth starting in mid-1990s). The availability of stock market data for each country is reported in Table A1 in Appendix A.
} 
In Figures 1 and 2, we show the global uncertainty index developed in Equation (1) to (3) and the U.S. uncertainty index. ${ }^{8}$ In each Figure the black line shows the 12-month moving average of the index and the horizontal broken line shows 1.65 standard deviations. We follow Bloom (2009) and Jurado et al. (2015) in defining uncertainty shocks as those events which exceed 1.65 standard deviations. By comparing Figure 1 with Figure 2, several points can be made.

The statistically significant global uncertainty shocks shown in Figure 1 are associated with Black Monday (October and November 1987), the Russian Default (September 1998), the 9/11 terrorist attack (September 2001), WorldCom (July 2002), the Gulf War II (February 2003), and the Global Financial Crisis (GFC) between 2007-2008. The non-economic statistically significant global uncertainty shocks, the 9/11 attack and Gulf War II, are smaller than the economic statistically significant global uncertainty shocks in Figure 1. The statistically significant global uncertainty shocks shown in Figure 1 are closely associated with statistically significant U.S. uncertainty shocks in Figure 2.

On Monday, October 19, 1987 stock markets around the world collapsed. The fall started in Hong Kong, spread west to Europe, and in the United States while the Dow Jones Industrial Average fell by 22.6\%. Globally, stock market losses persisted, with markets in Hong Kong, the United Kingdom, and the United States down by 45.5\%, 26.5\%, and 22.7\% respectively, at the end of October, 1987. Despite October 19, 1987 being the biggest daily percentage decline in the history of the Dow Jones Index, no major (news) event has been associated with the stock market crash. Both monthly U.S. stock market volatility and monthly global stock market volatility were high during October 1987.

On August 17, 1998 the Russian Central Bank devalued the rubble and the Russian government defaulted on its debt. The background to these developments included high

\footnotetext{
${ }^{8}$ Note that the last is just the stock market volatility index constructed with only the data for the U.S. stock market.
} 
inflation (Russian inflation was over 80\% during 1998) and the loss of foreign exchange reserves associated with decreased revenues from the export of crude oil and other commodities associated on falling prices and weak demand in the aftermath of the Asian Financial Crisis in late 1997. The Russian devaluation and default caused the Long Term Capital Management hedge fund to default on financial contracts worth billions of dollars, leading the Federal Reserve Bank of New York to orchestrate a rescue effort to avert a major financial collapse. During this episode, monthly U.S. stock market volatility was highest during August 1998, as was global stock market volatility.

The 9/11 terrorist attack in September 2001 is associated with spikes in volatility in both monthly U.S. stock market volatility and monthly global stock market volatility. In July 2002 large overstated revenues were uncovered in an accounting scandal at WorldCom and monthly U.S. and global stock market volatility spikes. A series of accounting scandals had started at Enron in December 2001 and at a number of large companies, including WorldCom, throughout 2002.

The Gulf War II started on March 19 and continued to May 1 in 2003. Monthly U.S. and global stock market volatilities increased sharply in February 2003 in anticipation of the U.S. invasion of Iraq. Over the next three months, global stock market volatility fell to somewhat less than half the value achieved in February 2003, before rising to about $73 \%$ of the February 2003 level in June 2003. By contrast, monthly U.S. stock market volatility fell to a very low value in March 2003, and achieved values from April to June 2003 of between $73 \%$ and $89 \%$ of the value in February 2003. The implications of this pattern of volatility is that, in the moving average plots of data in Figures 1 and 2, over the period September 2001 to June 2003, monthly U.S. stock market volatility peaks in June 2003 (in the aftermath of the Gulf War II), whereas monthly global stock market volatility peaks in September 2002 (during the accounting scandals). 
The GFC includes several events described in detail in Table A3 (Appendix A). The crisis is associated with subprime mortgage crisis and the consequent bankruptcy of Lehman Brothers in September 2008 and the bailout of several financial institutions including Northern Rock in UK (February 2008) and Fannie Mae and Freddie Mac (July 2008) and American International Group (September 2008) in U.S.

Standard \& Poor downgraded U.S. sovereign debt from AAA to AA+ on August 5, 2011. Both U.S. stock market volatility and global stock market volatility spiked in August 2011. The 12-month moving average for volatility peaked in May 2012 in global stock markets and in September 2011 in the U.S. stock market. This difference in timing is apparent in comparison of Figures 1 and 2.

The uncertainty associated with the Monetary Cycle turning point (October 1982), the Gulf War I (October 1990), and the Asian Crisis (November 1997) are statistically significant in the U.S. data depicted in Figure 2, but not in the global data represented in Figure 1. The market volatility during the Monetary Cycle turning point is identified with uncertainty over the effectiveness of policy during the Reagan administration at dealing with inflation and recession. The global uncertainty shock associated with the Monetary Cycle turning point is not statistically significant in Figure 1. Both the monthly volatility and the 12-month moving average volatility for the global stock markets peak in September 1982 and fall in the following months. The monthly volatility in the U.S. data also peaks in September 1982 and then falls in following months. The 12-month moving average volatility for the U.S. stock market has a peak in September 1982, a peak exceeded slightly in November 1982 and in January 1983, with high values over the whole period September 1982 to September 1983. Overall, the Monetary Cycle turning point is a much more important uncertainty event in the U.S. data than in the global data.

\subsection{Relative importance of high uncertainty events in U.S. and global data}


Table 1 reports the correlation of the lag structure between global uncertainty and the measure of U.S. uncertainty. The contemporaneous correlation between global and U.S. uncertainties is 0.16 . The other correlations in Table 1 are less than this 0.16 with two exceptions. The exceptions are that the correlation of U.S. uncertainty and global uncertainty lagged one is 0.89 and lag two is 0.208 . The implication of the 0.89 correlation is that if in June global uncertainty is high, then, in July U.S. uncertainty is likely to be high.

Table 2 reports Granger causality test between global uncertainty and U.S. uncertainty. The test results show that the null hypothesis that global uncertainty Granger does not cause U.S. uncertainty can be rejected at $1 \%$ level of confidence with lags of $1,3,6$ and 12 months. The null hypothesis that U.S. uncertainty Granger does not cause global uncertainty cannot be rejected with lags of 1 and 12 months. The correlation and Granger causality results support the idea that the measures of U.S. uncertainty and global uncertainty are not interchangeable, and that for the most part U.S. uncertainty is not driving the measure of global uncertainty.

In Figure 3 the global and U.S. volatility indices are scaled so that mean volatilities are equal. Figure 3 illustrates that the Monetary Cycle turning point, the Gulf War I, and the Asian Crisis are relatively less important in the global data, compared with other high uncertainty periods, than in the U.S. data. In contrast, in Figure 3, Black Monday, the Russian Default, the 9/11 terrorist attack, and WorldCom and associated accounting scandals are relatively more important compared with other high uncertainty periods in the global data than they are in the U.S. data. The last three major episodes, Gulf War II, GFC, and the downgrade of the U.S. sovereign debt are of approximately equal relative importance compared to other high uncertainty periods in the U.S. and global data.

\section{Modelling the effect of global uncertainty on the global economy}




\subsection{The FAVAR model}

Following Bloom (2009) and Jurado et al. (2015), who run VAR models, we run a FAVAR model to estimate the impact of uncertainty on key macroeconomics variables. The endogenous variables in the model include the growth in global output $\Delta\left(G I P_{t}\right)$, global inflation $\Delta(G C P I)_{t}$, global interest rate (based on central bank official/policy interest rates) $G I R_{t}$ and global uncertainty variable $G U_{t}$. The global macroeconomic variables are factors of variables available on the U.S., non-U.S. developed economies, and emerging economies from DGEI, Federal Reserve Bank of Dallas, for the G40 countries.

A structural VAR model of order $p$ is utilized:

$$
A_{0} y_{t}=c_{0}+\sum_{i=1}^{p} A_{i} y_{t-i}+\varepsilon_{t},(4)
$$

where $y_{t}=\left(\Delta\left(G I P_{t}\right), \Delta\left(G C P I_{t}\right), G I R_{t}, G U_{t}\right)$ is a $(m=4) \times 1$ vector of endogenous variables, $A_{0}$ denotes the $4 \times 4$ contemporaneous coefficient matrix, $c_{0}$ represents a $4 \times 1$ vector of constant terms, $A_{i}$ refers to the $4 \times 4$ autoregressive coefficient matrices, and $\varepsilon_{t}$ stands for a $4 \times 1$ vector of structural disturbances. ${ }^{9}$ To construct the structural VAR model representation, the reduced-form VAR model is consistently estimated using the least-squares method and is obtained by multiplying both sides of Equation (4) by $A_{0}^{-1}$. The reduced-form error term is $e_{t}=A_{0}^{-1} \varepsilon_{t}$ and is assumed to be Gaussian distributed.

The identifying restrictions on $A_{0}^{-1}$, is a lower-triangle coefficient matrix in the structural VAR model. This set up follows Christiano et al. (2005), Bekaert et al. (2014), and Jurado et al. (2015) in placing the output variable first, followed by global consumer price index (CPI), global interest rate and global uncertainty. ${ }^{10}$ The ordering of the variables assumes that the macroeconomic aggregates of output and CPI do not respond contemporaneously to shocks to the monetary policy of interest rate. The information of the

\footnotetext{
${ }^{9}$ We follow Bloom (2009) and Jurado et al. (2015) in setting $p=12$ which allows for a potentially long-delay in effects of uncertainty shocks on the economy and for a sufficient number of lags to remove serial correlation.

${ }^{10}$ Note we omitted the variables stock prices, wages, working hours and employment as these variables are not available at global level.
} 
monetary authority within a month $t$ consists of current and lagged values of the macroeconomic aggregates and past values of the uncertainty. The uncertainty variable ordered last captures the fact that the uncertainty is a stock market based variable and responds instantly to monetary policy shocks. The structural shocks to the dynamic responses of an endogenous variable are then identified using a Cholesky decomposition.

\subsection{Data and global macroeconomic variables}

The data for both the global uncertainty index and the VAR models are monthly from January 1981 to December 2014. Before 1981, data are not available for most variables from many developing countries. Data description, source and period availability is presented in Table A2.

The global factors: $G I R_{t}, G C P I_{t}$, and $G I P_{t}$ are estimated using data on emerging economies, advanced economies (excluding the U.S.), and the U.S. The data on interest rate, CPI and industrial production are taken from DGEI, Federal Reserve Bank of Dallas for the G40 countries. In DGEI weights (based on shares of world GDP (PPP)) are applied to the official/policy interest rates (determined by central banks) in levels and are applied to the indexes for industrial production and headline price indexes in growth rates to construct indices for emerging economies and advanced economies (excluding the U.S). In 2014 on a GDP PPP basis the G40 economies account for $83 \%$ of global GDP, and within the G40, the U.S., 19 advanced economies (excluding the U.S.), and 20 emerging economies account for $18 \%, 25 \%$, and $40 \%$, respectively, of global GDP. Combined, the 20 largest emerging economies on a PPP basis are now almost as big as the 20 largest developed economies. $G I R_{t}, G C P I_{t}$, and $G I P_{t}$ are the leading principal components given by:

$$
\begin{aligned}
& G I R_{t}=\left[I R_{t}^{A d}, I R_{t}^{U S}, I R_{t}^{E m}\right], \\
& G C P I_{t}=\left[C P I_{t}^{A d}, C P I_{t}^{U S}, C P I_{t}^{E m}\right], \\
& G I P_{t}=\left[I P_{t}^{A d}, I P_{t}^{U S}, I P_{t}^{E m}\right],
\end{aligned}
$$


where the superscripts US, Ad and Em represent the United States, advanced economies (excluding the U.S) and emerging economies. ${ }^{11}$

\section{The FAVAR model results}

The reduced-form VAR model of Equation (4) is consistently estimated by the ordinary least square method. We utilize the resulting estimates to construct the structural VAR representation of the model. The dynamic effect is examined by the impulse responses of global output growth, global inflation and interest rate to the structural global uncertainty shocks. We present the responses to one-time global uncertainty shocks as well as to the historical episodes of the uncertainty shocks.

\subsection{The effects of global uncertainty shocks on the economy}

Figure 4 shows the impact of one standard deviation global uncertainty shocks on global industrial production growth, global CPI inflation and global interest rate, for the FAVAR estimation. The dashed lines represent a one standard error confidence band around the estimates of the coefficients of the impulse response functions. We utilize the impulse response functions in Figure 4 to assess the timing and magnitude of the responses to onetime global uncertainty shock in the economy.

On the left hand side of Figure 4, the lags in the VAR system estimated are indicated. The FAVAR model is estimated with 3, 6 and 12 lags. The second, third and fourth columns in Figure 4 show responses of global interest rate, global CPI inflation and global industrial production growth to global uncertainty shocks. The results are summarized as follows:

\footnotetext{
${ }^{11}$ We deal with missing data in early observations for some series by building the factors with series available to maximise the number of time series observations.
} 
- Global uncertainty shocks are associated with a quick and sharp decline in global industrial production growth, which is greatest after 4 to 8 months depending on the specification.

- Global uncertainty shocks are associated with a quick and sharp decline in global CPI reaching the greatest point of decline after 6 months. However, when 12 lags are used in the VAR system, greatest point of decline occurs after 10 months.

- Global uncertainty shocks are associated with a decline in global interest rate; when 3 and 6 lags are used in the VAR systems the greatest decline in the global interest rate is observed after 16 months. ${ }^{12}$

\section{Are global uncertainty shocks different from U.S. uncertainty shocks for the global economy?}

Given that the U.S. is the world's largest financial centre, we disaggregate the effects of U.S. uncertainty $\left(U S U_{t}\right)$ and global uncertainty. U.S. uncertainty is estimated as a volatility index of the U.S. stock market. The new vector of endogenous variables is a $(m=5) \times 1$ vector of endogenous variables: $y_{t}=\left(\Delta\left(G I P_{t}\right), \Delta\left(G C P I_{t}\right), G I R_{t}, U S U_{t}, G U_{t}\right)$, and $A_{0}$ denotes the $5 \times 5$ contemporaneous coefficient matrix. More precisely, the Cholesky lower triangle contemporaneous matrix is estimated by postulating the following $A_{0} y_{t}$ matrix form:

$$
\left[\begin{array}{ccccc}
1 & 0 & 0 & 0 & 0 \\
a_{11} & 1 & 0 & 0 & 0 \\
a_{21} & a_{22} & 1 & 0 & 0 \\
a_{31} & a_{32} & a_{33} & 1 & 0 \\
a_{41} & a_{42} & a_{43} & 0 & 1
\end{array}\right]\left[\begin{array}{c}
\Delta\left(G I P_{t}\right) \\
\Delta\left(G C P I_{t}\right) \\
G I R_{t} \\
U S U_{t} \\
G U_{t}
\end{array}\right]
$$

\footnotetext{
${ }^{12}$ Note that when the models are specified with 12 lags, the greatest response occurs after 6 months, with a quick return to positive values after 12 months. This pattern is only observed for FAVAR model and for the FABVAR model Wishart type of priors in models with a 12 month lag. Even with a 12 month lag structure, the FABVAR model with Minnesota and Sims-Zha priors results are similar to those obtained in the FAVAR and FABVAR models with 3 month and 6 month lags.
} 
where $U S U_{t}$ represents the U.S. uncertainty shock derived from the volatility of the U.S. stock market. Note that the coefficient $a_{44}$ is set to be zero, implies that we do not have preference in terms of ordering both U.S. and global uncertainty first in the Cholesky decomposition. ${ }^{13}$

Figure 5 shows the responses of global industrial production, CPI and interest rate to global uncertainty shocks (first row) and U.S. uncertainty shocks (second row). In the first column a one-standard deviation shock to global uncertainty decreases global industrial production by -0.13 and a one-standard deviation shock to U.S. uncertainty reduces global industrial production by less than -0.06 . The global uncertainty shock is statistically significant over a more extended period of time. The global and U.S. uncertainty shocks are statistically significant over 1 to 16 month and 1 to 10 month horizons, respectively. The impact of global and U.S uncertainty shocks also differ in effects on global CPI. While the response of global CPI to global uncertainty shocks is statistically significant and reaches a minimum of -0.08 , the impact of U.S. uncertainty shocks on global CPI is much smaller and is not statistically significant at conventional levels.

Finally, the global interest rate is negatively affected by a positive global uncertainty shock but the effect is only marginally statistically significant. The response of global interest rate to U.S uncertainty shocks is much smaller and is not statistically significant.

\section{Does the source of uncertainty shocks matter for the global economy?}

In this we show that global uncertainty shocks have different sources. We analyse the impact of global uncertainty shocks by source on the global economy. In particular, we decompose global uncertainty shocks into global financial and non-financial shocks, where

\footnotetext{
${ }^{13}$ We also estimate the Cholesky contemporaneous restriction matrix allowing $a_{44}$ to be estimated and order both U.S and global uncertainty first and be estimated in separate models. Results are almost identical to those presented in Figure 5.
} 
all the shocks considered are those shocks which exceed 1.65 standard deviations in terms of monthly observations.

\subsection{Financial vs. non-financial uncertainty shock}

In this subsection, we distinguish between financial and non-financial shocks and estimate the impact effects of both shocks on the global economy. Shocks originating in economic or financial disruption may have been amenable to better economic policy design whereas those due to war or terrorism are not (although political policies might have an impact). Examination of uncertainty shocks with an economic/financial source might lead to a better understanding of how economic policy might be designed to both; avoid and mitigate the effects of future shocks.

Our definition of global financial shocks comprises the following events which exceeded 1.65 standard deviations: Black Monday, Russian Default, WorldCom, and the GFC. The global financial crisis includes the five main events are described in Table A3 (Appendix A). These are North Rock emergency funding in September 2007 and the nationalisation in February 2008, the bailout of Fannie Mae and Freddie Mac, the Lehman Brothers bankruptcy and the bail out of American International Group (AIG) in the U.S in the period July 2008, September 2008 and October 2008 (respectively). The Non-financial uncertainty shocks which exceed 1.65 standard deviations are the Gulf War II and 9/11 terrorist attack.

To disaggregate global uncertainty shocks we modify the system of equations presented in equation by subtitling the unique variable $G U_{t}$ into two different uncertainty shocks: $D F * G U_{t}$ and $D N F * G U_{t}$, where the first variable the global financial uncertainty shock is constructed by interacting the $G U_{t}$ index with a dummy variable $D F_{t}$, which takes the value of 1 when a financial shock occurs and 0 otherwise (details of the period dummies 
can be found in Appendix A, Table A4). ${ }^{14}$ The second variable (the non-financial uncertainty shocks) is constructed by interacting the $G U_{t}$ index with a dummy variable $D N F_{t}$, which takes the value of 1 when a non-financial shock occurs and 0 otherwise. ${ }^{15}$ The new vector of endogenous variables is a $(m=5) \times 1$ vector, that is $y_{t}=\left(\Delta\left(G I P_{t}\right), \Delta\left(G C P I_{t}\right), G I R_{t}, F D_{t} *\right.$ $\left.G U_{t}, D N F_{t} * G U_{t}\right)$. The Cholesky lower triangle contemporaneous matrix is estimated using the following $A_{0} y_{t}$ matrix:

$$
\left[\begin{array}{ccccc}
1 & 0 & 0 & 0 & 0 \\
a_{11} & 1 & 0 & 0 & 0 \\
a_{21} & a_{22} & 1 & 0 & 0 \\
a_{31} & a_{32} & a_{33} & 1 & 0 \\
a_{41} & a_{42} & a_{43} & 0 & 1
\end{array}\right]\left[\begin{array}{c}
\Delta\left(G I P_{t}\right) \\
\Delta\left(G C P I_{t}\right) \\
G I R_{t} \\
D F_{t} * G U_{t} \\
D N F_{t} * G U_{t}
\end{array}\right]
$$

We set $a_{44}$ to be zero, since there is no good reason to impose an order on financial and non-financial uncertainty. ${ }^{16}$

Figure 6 compare the impacts of financial and non-financial uncertainty shocks on key global macroeconomic variables. In the first and second rows we show the impact of financial and non-financial uncertainty shocks (respectively) on global industrial production (first column), CPI (second column) and interest rate (third column).

Results in the first column suggest that financial uncertainty shocks have a much larger impact in absolute value than the non-financial shocks in reducing global industrial production (up to -0.17 and -0.10 , respectively). It is also observed that the impact of financial shocks on global industrial production is faster. The greatest impact of financial shocks on global industrial production is observed between 6 to 10 months later, compared to 11 to 16 months later for non-financial shocks. More remarkable are the differences between

\footnotetext{
${ }^{14}$ Note that the dummy variables only take the value of 1 when the identified shock exceeds 1.65 standard deviations following Bloom (2009).

${ }^{15}$ Note that we slightly innovate with respect of Bloom (2009), who uses only a single dummy variable which takes the value of 1 when the uncertainty shock occurs and 0 otherwise. The reason for doing that is because Bloom (2009)'s definition does not capture the magnitude of the shock. By interacting the $G U_{t}$ and a dummy variable the shocks now also capture the dimension of the shocks.

${ }^{16}$ Note that either eliminating the zero restriction on $a_{44}$ and/or changing the order financial and non-financial uncertainty shocks do not alter the main results.
} 
the responses of Global CPI to those shocks. Financial uncertainty shocks have a negative effect on global CPI that is statistically significant at conventional levels. By contrast, nonfinancial shocks do not have a statistically significant effect on global CPI. In the third column of Figure 6, it is observed that central banks eventually reduce interest rates by similar amounts after both financial and non-financial shocks.

\subsection{Variance decomposition of global macroeconomic variables to financial and non- financial uncertainty shocks}

Table $3 \mathrm{a}$ ), b) and c) report the fractions of forecast error variance decomposition (FEVDs) for the global industrial production, global CPI and global interest rate (respectively) contributed by all the variables, including global financial uncertainty and global nonfinancial uncertainty. Global industrial production growth, global inflation, global interest rate and global financial uncertainty each makes statistically significant contributions to forecasting the variation in global industrial production. The contribution of global financial uncertainty explains $18.26 \%$ of the variation in global growth after 48 months. By contrast, global non-financial uncertainty explains only $7.75 \%$ of the variation in global growth (that is not statistically significant) after 48 months. After 48 months, global inflation and global interest rate forecast $19.74 \%$ and $3.67 \%$ of variation in global growth.

Global industrial production growth, global interest rate, and global financial uncertainty each makes statistically significant contributions to forecasting the variation in global inflation, while global non-financial uncertainty does not. The contribution of global financial uncertainty explains $14.95 \%$ of the variation in global inflation after 48 months. In contrast to the effect on global industrial production, the global interest rate explains a large fraction variation (25.20\%) in global inflation after 48 months. Only global growth explains a statistically significant fraction (10.60\% after 48 months) of the variation in global interest rate. 
In summary, the forecast error variance decomposition results indicate that global financial uncertainty explains statistically significant fractions of the variation in global growth and global inflation over 48-month horizons, while global non-financial uncertainty does not. At the 48-month horizon, global financial uncertainty accounts for $18.26 \%$ and $14.95 \%$ of the variation in global growth and global inflation, respectively.

\section{Effect of global uncertainty in presence of local uncertainty for domestic economies}

To determine whether the effect of global uncertainty on local macroeconomic variables is robust to the inclusion of local uncertainty, we re-estimate the SVAR for largest developed and developing economies with both global and domestic uncertainty included as variables. The models are estimated separately for each economy.

The model is described in Equations 10 and 11, where the first four variables in the SVAR system are variables for a specific economy and the last variable is global uncertainty. The endogenous variables in the model can be summarised as follows:

$$
y_{t}=\left(\Delta\left(D I P_{t}\right), \Delta\left(D C P I_{t}\right), D I R_{t}, D U_{t}, G U_{t}\right),
$$

where $D I P_{t}$ is domestic industrial production, $D C P I_{t}$ is domestic CPI, $D I R_{t}$ is domestic interest rate set by the central bank, $D U_{t}$, is domestic uncertainty which is the volatility index of the domestic stock market, and $G U_{t}$ is global uncertainty as described in previous models. The period estimated is also from January 1981 to December 2014, data definition, sources and period availability is presented in Table A5. ${ }^{17}$ The Cholesky lower triangle contemporaneous matrix is estimated using the following $A_{0} y_{t}$ matrix:

\footnotetext{
${ }^{17}$ Note that the starting period for these estimations start later than 1981 for some countries due to data availability. In particular, the starting period for Brazil is October 1996, January 1994 for China, January 1994 for India, January 1997 for Russia, and January 1990 for South Africa. For all other countries, the full period sample is available over January 1981 to December 2014.
} 


$$
\left[\begin{array}{ccccc}
1 & 0 & 0 & 0 & 0 \\
a_{11} & 1 & 0 & 0 & 0 \\
a_{21} & a_{22} & 1 & 0 & 0 \\
a_{31} & a_{32} & a_{33} & 1 & 0 \\
a_{41} & a_{42} & a_{43} & a_{44} & 1
\end{array}\right]\left[\begin{array}{c}
\Delta(D I P) \\
\Delta\left(D C P I_{t}\right) \\
D I R_{t} \\
D U_{t} \\
G U_{t}
\end{array}\right]
$$

Results for the impulse responses of domestic output, domestic inflation and domestic interest rate appear in Figures 7a and 7b for the largest developed and developing economies respectively. Output declines significantly in each country with a rise in global uncertainty even controlling for domestic uncertainty, with the only exception being China (where the effect is negative but not statistically significant). The output of the US is less affected by global uncertainty than the output of the other countries (with the exception of China). China's economy may be less affected by global uncertainty due to be less integrated into the world economy than the other countries (for the period analysed). The US may be less affected by global uncertainty because of the size of the economy.

The output of countries significantly affected by shocks to global uncertainty include commodity dependant countries (Brazil and Russia), major advanced countries (France, Germany, Italy, Japan and the UK), and important emerging countries (India, Mexico, South Africa). The negative effect of global uncertainty on domestic output does not persist for as long in Japan as for most other countries, possibly due to relatively high levels of economic association with China’s economy.

The responses of inflation and the official interest to positive shocks to global uncertainty are mostly negative and consistent with the result for the negative effect of shocks to global uncertainty on output. For most economies, a positive shock to global uncertainty has a depressing effect on output and prices and central banks respond with a reduction in the official interest rate. The exceptions are for Brazil, Mexico and Russia.

For Brazil, Mexico and Russia, while an increase in global uncertainty is associated with depressed domestic output, the CPI and interest rate increased. In periods of high global 
uncertainty (e.g. global financial crisis), large capital outflows take place in these economies triggering higher inflation. In consequence, the interest rate also increases to reduce capital outflows. Shaghil and Zlate (2013) document large capital outflow for both Asian emerging economies and Latin American economies during investor panic after the Lehman Brothers bankruptcy in 2008 (period of high global uncertainty). Obstfeld et al. (2009) detail that Mexico, Brazil and Russia experience large currencies depreciations (above the average depreciation experienced by other emerging economies) during 2008 global financial crisis.

\section{Robustness analysis}

We perform several robustness analyses including: a reverse ordering of variables in the Cholesky-VAR system and Bayesian estimations. In Supplementary material 1, we reproduce all estimations from the previous sections using a Factor Augmented Bayesian Vector Autoregressive Model (FABVAR). This methodology utilizes Bayesian analysis to capture uncertainty in the parameter estimation and in the precision of the reliability of inferences. As long as the prior distributions are proper, the lack of identification restrictions poses no conceptual problems in the Bayesian analysis because the posterior distributions are proper.

In the Supplementary Material 1, we show results for three different priors: Minnesota, Normal-Wishart and Sims-Zha. The Minnesota prior involves setting the regression coefficients toward zeros and lessening the over fitting risk in the VAR estimation. The Normal-Wishart/Sims-Zha priors provide a full Bayesian treatment of the regression coefficients and the elements of variance covariance matrix as unknown parameters in order to reflect parameter uncertainty more accurately. The results (discussed in detail in Supplementary Material) show that setting Normal-Wishart/Sims-Zha priors leads to the prediction similar to the FAVAR estimates, in that the non-informative priors do not do any 
of the shrinkage. The impulse response functions show smoother patterns by utilizing Minnesota shrinkage priors which show to be very important in the VAR modelling. Overall these results are similar to the finding by the FAVAR model.

We also re-estimate the FAVAR models using a reverse ordering of variables in the Cholesky-VAR system as proposed by Bloom (2009). ${ }^{18}$ These results confirm the sign and statistically significance of results from the main models estimated in the before.

\section{Conclusions}

In this paper we examine the impact of global uncertainty on the global economy and on large developed and developing economies. This supplements the recent literature analysing the effects of uncertainty (either U.S. or global) on country level macroeconomic variables. Using principal component analysis of the stock market volatility indexes for the largest 15 economies a measure on global uncertainty is identified. Taking advantage of the new global database from DGEI from the Federal Reserve Bank of Dallas, we explore the impact of global uncertainty on key global macroeconomic variables to then explore its effect on largest developed and developing economies.

We found that global uncertainty shocks are associated with a sharp decline in global industrial production, global inflation and global interest rate. The maximum decline of industrial production and global inflation occurs six months after a global uncertainty shock, while the maximum decline in global interest rate occurs after 16 months after a global uncertainty shock. At country level, global uncertainty shocks (even controlling for domestic uncertainty) reduce outputs in most large developed and developing economies. Outputs in Russia, Brazil and South Africa are most affected by global uncertainty shocks while outputs of China and the U.S and U.K are less responsive to these shocks.

\footnotetext{
18 These results are available upon request from the Authors.
} 
We use the existing knowledge on important global events to distinguish between financial and non-financial uncertainty shocks. Our decomposition of global uncertainty shocks shows that global financial uncertainty shocks are more important (for the global economy) than non-financial uncertainty shocks. From 1981 to 2014 global financial uncertainty forecasts $18.26 \%$ and $14.95 \%$ of the variation in global growth and global inflation, respectively, while non-financial uncertainty shocks forecasts only $7.75 \%$ and $2.15 \%$ of the variation in global growth and global inflation, respectively.

\section{References}

Arellano, C., Bai, Y., and Kehoe, P. Financial Markets and Fluctuations in Volatility. Federal Reserve Bank of Minneapolis Working Paper, 2010.

Bachmann, R., Elstner, S., and Sims, E.R., 2013. Uncertainty and Economic Activity: Evidence from Business Survey Data. American Economic Journal: Macroeconomics 5, 21749.

Baker, S. R., Bloom, N., and Davis, S. J., (2016). Measuring Economic Policy Uncertainty. The Quarterly Journal of Economics, 131(4), 1593-1636.

Baum, C. F., Caglaynan, M., and Talavera, O., 2010. On the Sensitivity of Firms' Investment to Cash Flow and Uncertainty. Oxford Economic Papers 62, 286-306.

Bekaert, G., Hoerova, M., and Duca, M.L., 2013. Risk, Uncertainty and Monetary Policy. Journal of Monetary Economics 60, 771-788.

Berger, T. and Herz, S., 2014. Global Macroeconomic Uncertainty. Working paper, available at https://www.gwu.edu/ forcpgm/BergerHerz_gmu.pdf.

Bloom, N., 2009. The Impact of Uncertainty Shocks. Econometrica 77, 623-685.

Bloom, N., Bond, S., and Van Reenen, J., 2007. Uncertainty and Investment Dynamics. Review of Economic Studies 74, 391-415.

Bredin, D. and Fountas, S., 2009. Macroeconomic Uncertainty and Performance in the European Union. Journal of International Money and Finance 28, 972-986.

Charemza, W., Díaz, C., and Makarova, S., 2015. Conditional Term Structure of Inflation Forecast Uncertainty: The Copula Approach. University of Leicester Working Paper No. $15 / 07$. 
Christiano, L. J., Eichenbaum, M., and Evans, C. L., 2005. Nominal Rigidities and the Dynamic Effects of a Shock to Monetary Policy. Journal of Political Economy 113, 1-45.

Delrio, S., 2016. Estimating the Effects of Global Uncertainty in Open Economies. Working paper, available at SSRN 2832727.

Favero, C., 2009. Uncertainty and the Tale of two Depressions: Let Eichengreen and O'Rourke meet Bloom. VoxEU 2009.

Fernández-Villaverde, J., Guerrón-Quintana, P., Rubio-Ramírez, J. F. and Uribe, M., 2011. Risk Matters: The Real Effects of Volatility Shocks. American Economic Review 6, 2530-61

Gilchrist, S., Sim, J. W., and Zakrajsek, E., 2010. Uncertainty, Financial Frictions, and Investment Dynamics. Society for Economic Dynamics 2010 Meeting Paper 1285.

Grossman, V., Mack, A., and Martinez-Garcia, E., 2014. Database of global economic indicators (DGEI): a methodological note, Globalization and Monetary Policy Institute Working Paper 166, Federal Reserve Bank of Dallas.

Hirata, H., Kose, M. A., Otrok, C., Terrones, M. E., 2012. Global House Price Fluctuations: Synchonization and Determinants. NBER Working Paper 18362, available at http://www.nber.org/papers/w18362.

Jurado, K., Ludvigson, S. C. and Ng, S., 2015. "Measuring Uncertainty." American Economic Review 105, 1177-1216.

Knotek, E. S., and Khan, K., 2011. How Do Households Respond to Uncertainty Shocks? Federal Reserve Bank of Kansas City Economic Review 96, 5-34.

Leduc, Sylvain and Zheng Liu. 2015. Uncertainty Shocks are Aggregate Demand Shocks. Federal Reserve Bank of San Francisco, Working Paper 2012-10.

Leahy, J. V., and Whited, T.M., 1996. The Effect of Uncertainty on Investment: Some Stylized Facts. Journal of Money, Credit and Banking 28, 64-83.

Mumtaz, H., and Theodoridis, K., 2014. The international transmission of volatility shocks: an empirical analysis. Journal of the European Economic Association 13, 512-533.

Obstfeld, M., Shambaugh, J.C., and Taylor, A. M., 2009. Financial Instability, Reserves, and Central Bank Swap Lines in the Panic of 2008. American Economic Review 99, 480-86.

Ozturk, E. O., and Sheng, X. S., 2016. Measuring Global and Country-specific uncertainty. Working paper, available at http://www.pramu.ac.uk/wp-content/uploads/2016/04/Ozturkand-Sheng_Measuring-global-uncertainty.pdf.

Rossi, B. and Sekhposyan, T., 2015. Macroeconomic Uncertainty Indices Based on Nowcast and Forecast Error Distributions. American Economic Review 105, 650-55.

Shaghil, A., and Zlate, A., 2014. Capital flows to emerging market economies: A brave new world? Journal of International Money and Finance 48, 221-248. 
Table 1. Correlation of the lag structure between global and the U.S. uncertainty (cross correlogram)

\begin{tabular}{clccc}
\hline Global, U.S. (-i) & Global ,U.S.(+i) & i & lag & lead \\
\hline.$|++|$ &.$|++|$ & 0 & 0.165 & 0.165 \\
.$\|$ &.$|+++++++++|$ & 1 & 0.001 & 0.889 \\
.$\|$ &. $\mid++$ & 2 & 0.023 & 0.218 \\
.$|+|$ &.$\|$ & 3 & 0.049 & -0.008 \\
.$\|$ &.$|+|$ & 4 & 0.014 & 0.112 \\
.$|+|$ &.$|+|$ & 5 & 0.155 & 0.108 \\
.$\|$ &.$|+|$ & 6 & 0.036 & 0.051 \\
.$\|$ &.$|++|$ & 7 & -0.022 & 0.163 \\
.$|+|$ &.$|+|$ & 8 & 0.060 & 0.101 \\
.$\|$ &. $\mid$ & 9 & 0.043 & 0.010 \\
.$\|$ &.$|+|$ & 10 & -0.012 & 0.085 \\
.$\|$ &.$|+|$ & 11 & -0.019 & 0.118 \\
.$\|$ &.$\|$ & 12 & -0.004 & 0.030 \\
\hline
\end{tabular}

Note that in column 1 and 2 are only for optical view, + represents a value close to 0.1 correlation.

Table 2. Granger causality test between global and the U.S. uncertainty Null Hypothesis: $x$ does not Granger cause $y$

\begin{tabular}{lllll}
\hline Granger test/Lags & 1 & 3 & 6 & 12 \\
\hline $\begin{array}{l}\text { Global uncertainty does not granger } \\
\text { cause U.S. uncertainty }\end{array}$ & $1479.01^{* * *}$ & $496.04^{* * * *}$ & $237.05^{* * *}$ & $119.05^{* * *}$ \\
$\begin{array}{l}\text { U.S. Uncertainty does not granger } \\
\text { cause global uncertainty }\end{array}$ & 0.58 & $3.57^{* *}$ & $2.77^{* *}$ & 1.02 \\
\hline
\end{tabular}

Notes: ***, **, * indicates rejection of the null hypothesis at $1 \%, 5 \%$ and $10 \%$, levels of significance respectively. 
Table 3. Variance decomposition of global macroeconomic variables

a. Forecast error variance decomposition of global industrial production

\begin{tabular}{cccccc}
\hline $\begin{array}{c}\text { Contribution } \\
\text { from/months }\end{array}$ & Global IP & Global CPI & Global IR & $\begin{array}{l}\text { Financial } \\
\text { uncertainty } \\
\text { shock }\end{array}$ & $\begin{array}{l}\text { Non-financial } \\
\text { uncertainty } \\
\text { shock }\end{array}$ \\
\hline 1 & $100.00^{* * *}$ & 0.00 & 0.00 & 0.00 & 0.00 \\
6 & $85.99^{* * *}$ & 0.82 & 0.05 & $12.25^{* * *}$ & 0.88 \\
12 & $64.71^{* * *}$ & $10.86^{*}$ & 0.83 & $18.95^{* * *}$ & 4.66 \\
18 & $52.48^{* * *}$ & $19.78^{* *}$ & $2.70^{* *}$ & $17.26^{* * *}$ & 7.78 \\
24 & $51.21^{* * *}$ & $20.51^{* * *}$ & $3.43^{* *}$ & $16.85^{* * *}$ & 8.00 \\
30 & $51.44^{* * *}$ & $19.54^{* * *}$ & $3.28^{* *}$ & $18.11^{* * *}$ & 7.63 \\
36 & $50.71^{* * *}$ & $19.75^{* * *}$ & $3.46^{* *}$ & $18.35^{* * *}$ & 7.73 \\
48 & $50.58^{* * *}$ & $19.74^{* * *}$ & $3.67^{* *}$ & $18.26^{* * *}$ & 7.75 \\
\hline
\end{tabular}

Notes: $* * *, * *, *$ indicates rejection of the null hypothesis at $1 \%, 5 \%$ and $10 \%$, levels of significance respectively.

b. Forecast error variance decomposition of global CPI

\begin{tabular}{cccccc}
$\begin{array}{c}\text { Contribution } \\
\text { from/months }\end{array}$ & Global IP & Global CPI & Global IR & $\begin{array}{l}\text { Financial } \\
\text { uncertainty } \\
\text { shock }\end{array}$ & $\begin{array}{l}\text { Non-financial } \\
\text { uncertainty } \\
\text { shock }\end{array}$ \\
\hline 1 & 0.19 & $99.81^{* * *}$ & 0.00 & 0.00 & 0.00 \\
6 & 7.02 & $85.77^{* * *}$ & 0.24 & $5.44^{*}$ & 1.53 \\
12 & $14.95^{* *}$ & $66.66^{* * *}$ & 2.75 & $13.02^{* *}$ & 2.63 \\
18 & $18.95^{* *}$ & $54.21^{* * *}$ & $8.02^{*}$ & $16.64^{* *}$ & 2.17 \\
24 & $18.90^{* * *}$ & $47.68^{* * *}$ & $14.35^{* *}$ & $16.88^{* *}$ & 2.19 \\
30 & $18.02^{* * *}$ & $44.15^{* * *}$ & $19.52^{* *}$ & $16.08^{* *}$ & 2.22 \\
36 & $17.45^{* * *}$ & $41.99^{* * *}$ & $22.98^{* *}$ & $15.40^{* *}$ & 2.18 \\
48 & $17.31^{* * *}$ & $40.40^{* * *}$ & $25.20^{* *}$ & $14.95^{* *}$ & 2.15 \\
\hline
\end{tabular}

Notes: $* * *, * *, *$ indicates rejection of the null hypothesis at $1 \%, 5 \%$ and $10 \%$, levels of significance respectively.

c. Forecast error variance decomposition of global interest rate

\begin{tabular}{cccccc}
\hline $\begin{array}{l}\text { Contribution } \\
\text { from/months }\end{array}$ & Global IP & Global CPI & Global IR & $\begin{array}{l}\text { Financial } \\
\text { uncertainty } \\
\text { shock }\end{array}$ & $\begin{array}{l}\text { Non-financial } \\
\text { uncertainty } \\
\text { shock }\end{array}$ \\
\hline 1 & 2.86 & 0.03 & $97.11^{* * *}$ & 0.00 & 0.00 \\
6 & 4.20 & 0.09 & $95.24^{* * *}$ & 0.34 & 0.14 \\
12 & 6.95 & 0.07 & $91.06^{* * *}$ & 0.94 & 0.99 \\
18 & 9.21 & 0.10 & $87.51^{* * *}$ & 1.72 & 1.46 \\
24 & 10.36 & 0.23 & $85.21^{* * *}$ & 2.28 & 1.92 \\
30 & 10.64 & 0.36 & $84.27^{* * *}$ & 2.49 & 2.24 \\
36 & $10.62^{*}$ & 0.41 & $84.03^{* * *}$ & 2.53 & 2.41 \\
48 & $10.60^{*}$ & 0.42 & $83.97^{* * *}$ & 2.52 & 2.49 \\
\hline
\end{tabular}

Notes: ***,**,* indicates rejection of the null hypothesis at $1 \%, 5 \%$ and $10 \%$, levels of significance respectively. 
Figure 1. Global volatility index: 12-month moving average standard deviation

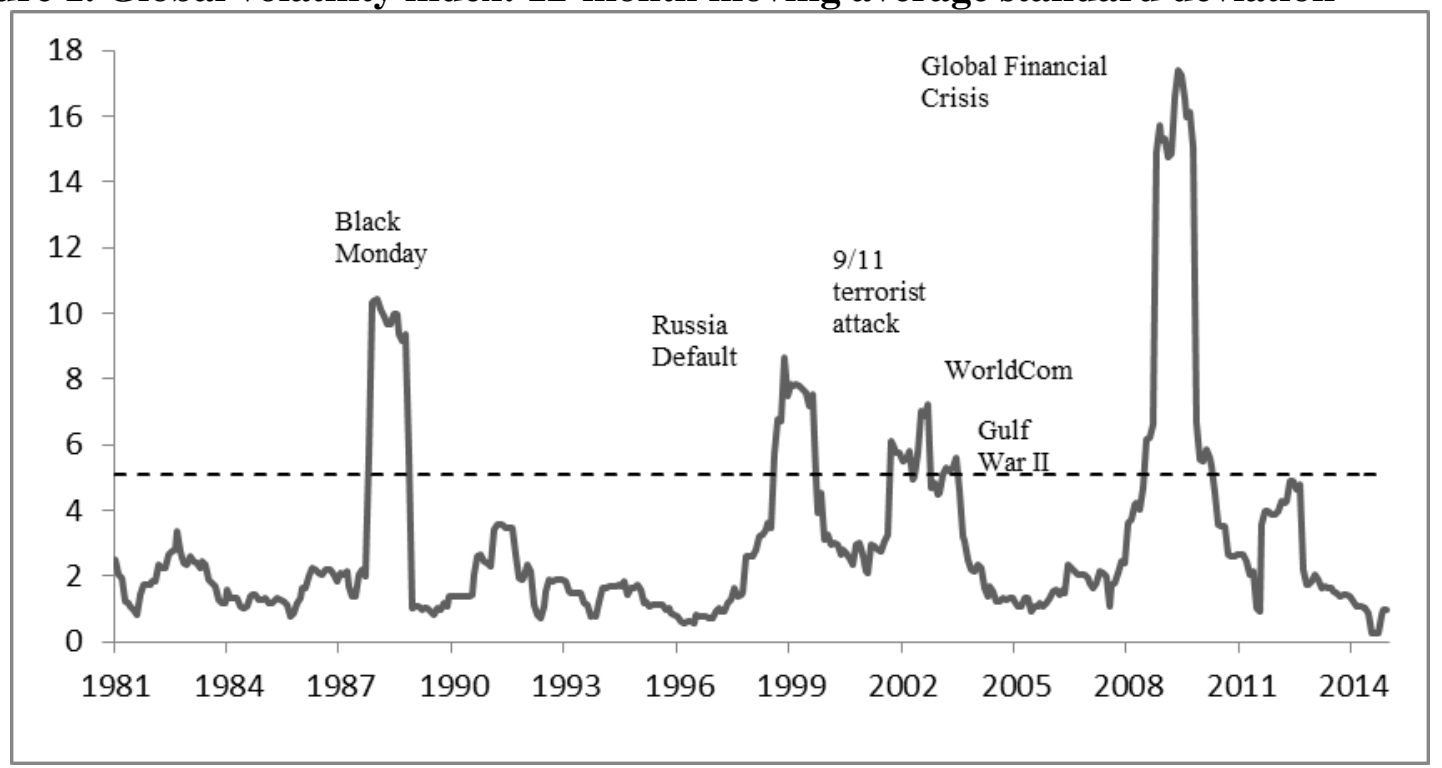

Figure 2. U.S. volatility index: 12-month moving average standard deviation

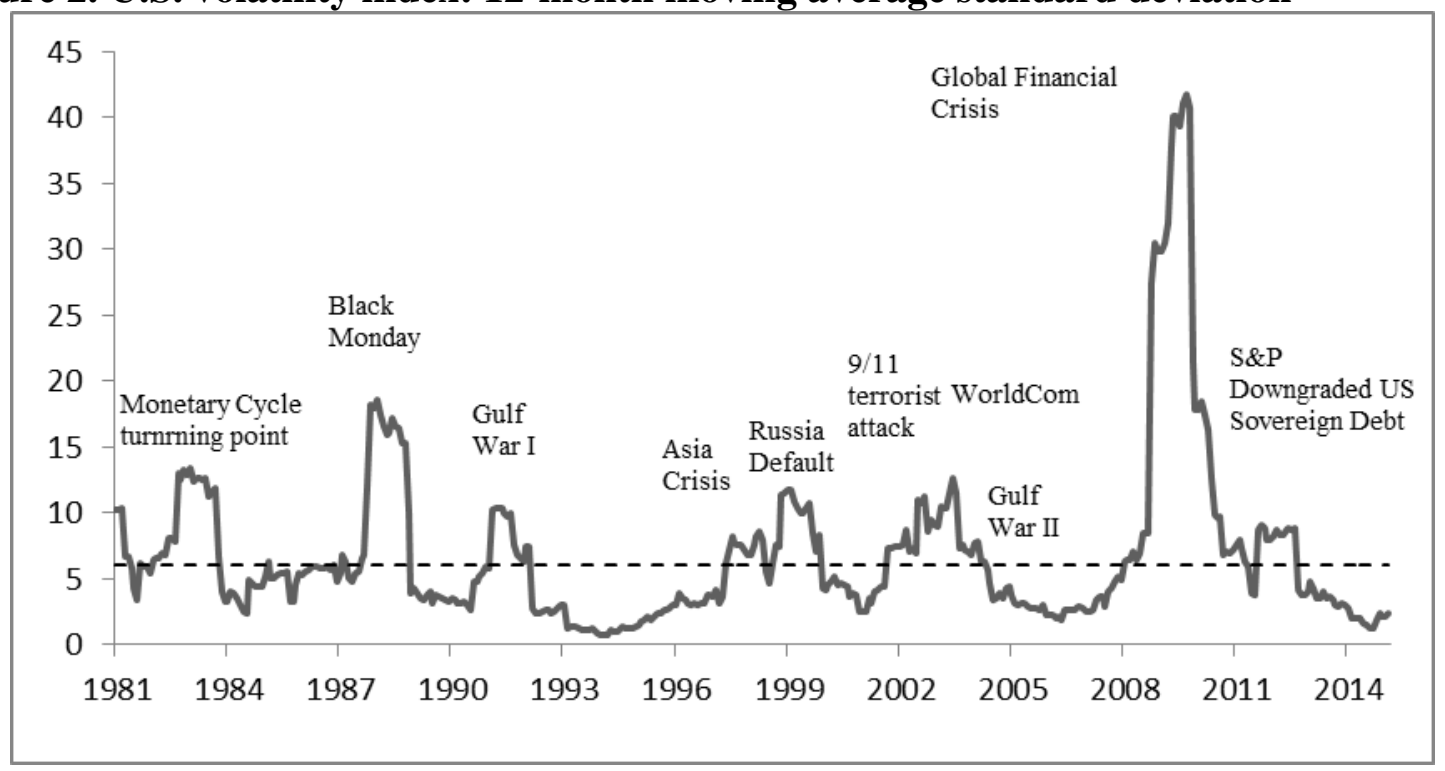

Figure 3. Global and U.S. volatility indices scaled so that mean volatilities are equal.

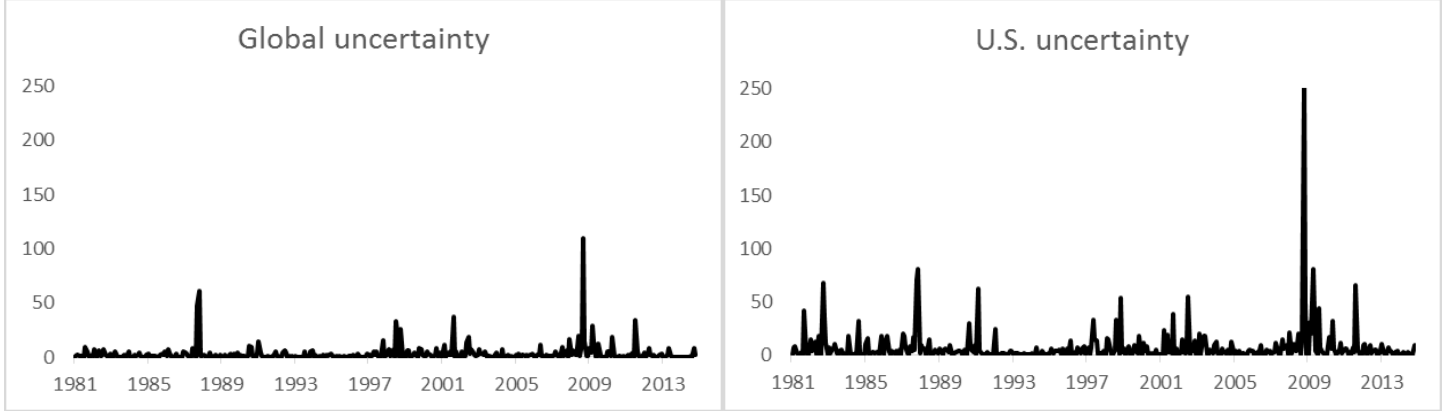


Figure 4. Responses of global industrial production, global inflation and global interest rate to global uncertainty shocks

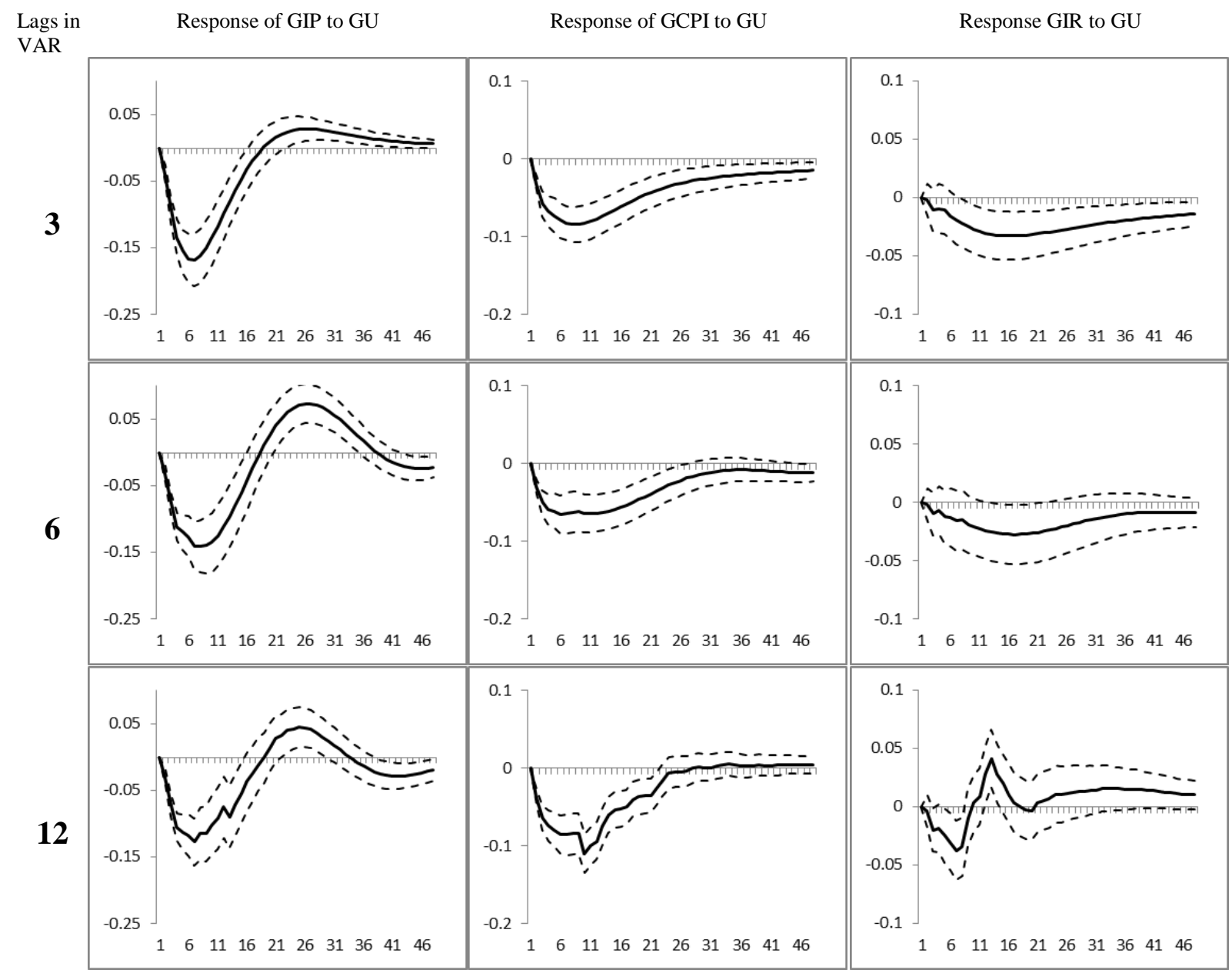

Notes: The dashed lines represent a one standard error confidence band around the estimates of the coefficients of the impulse response functions. The confidence bands are obtained using Monte Carlo integration as described by Sims (1980), where 5000 draws were used from the asymptotic distribution of the VAR coefficient. 
Figure 5. Responses of global variables to U.S. and global uncertainty shocks

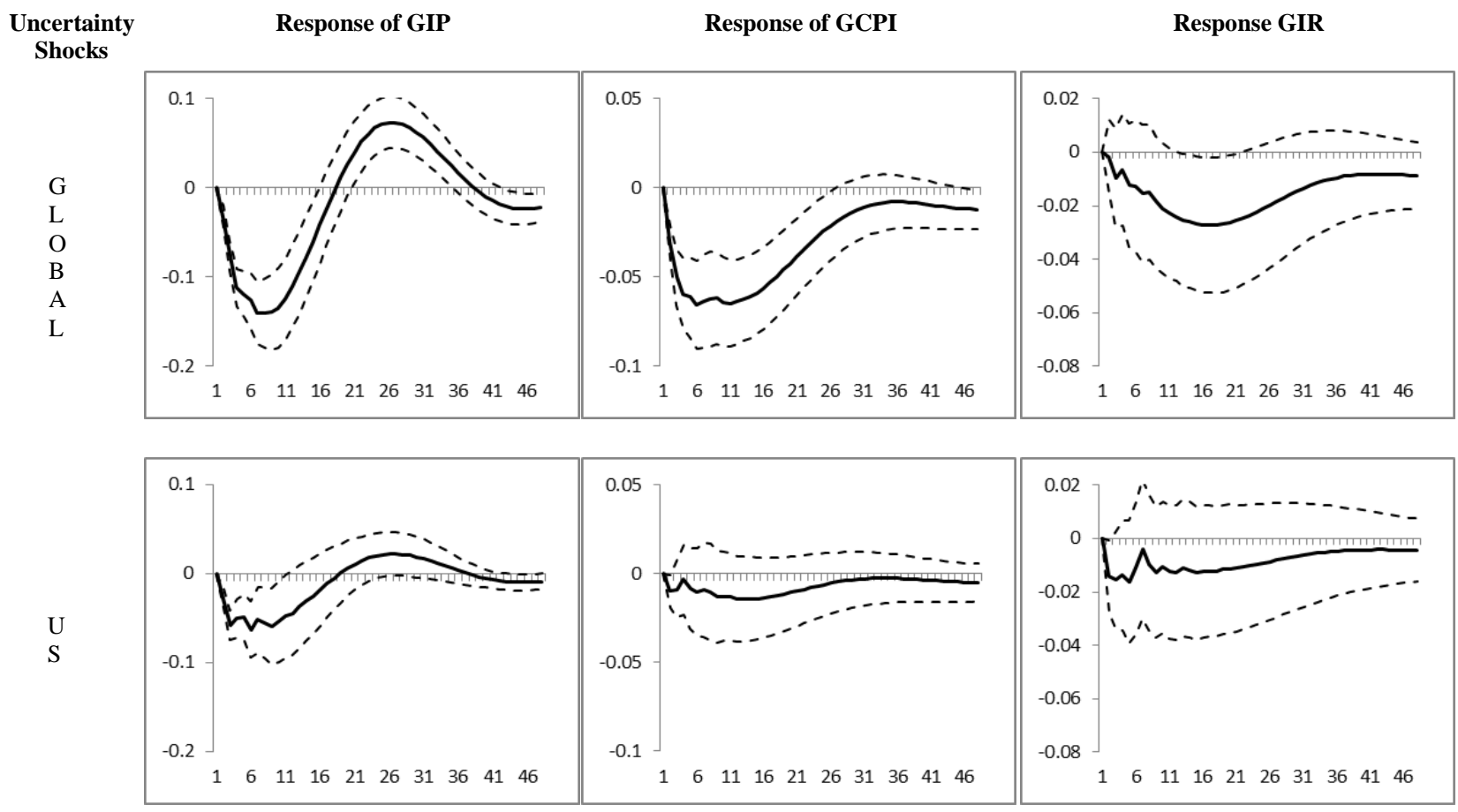

Notes: to conserve space we only report results when 6 lags are specified in the FAVAR system. Results for 3 and 12 lags are available from the authors upon request.

Figure 6. Responses of global variables to financial and non-financial uncertainty shocks
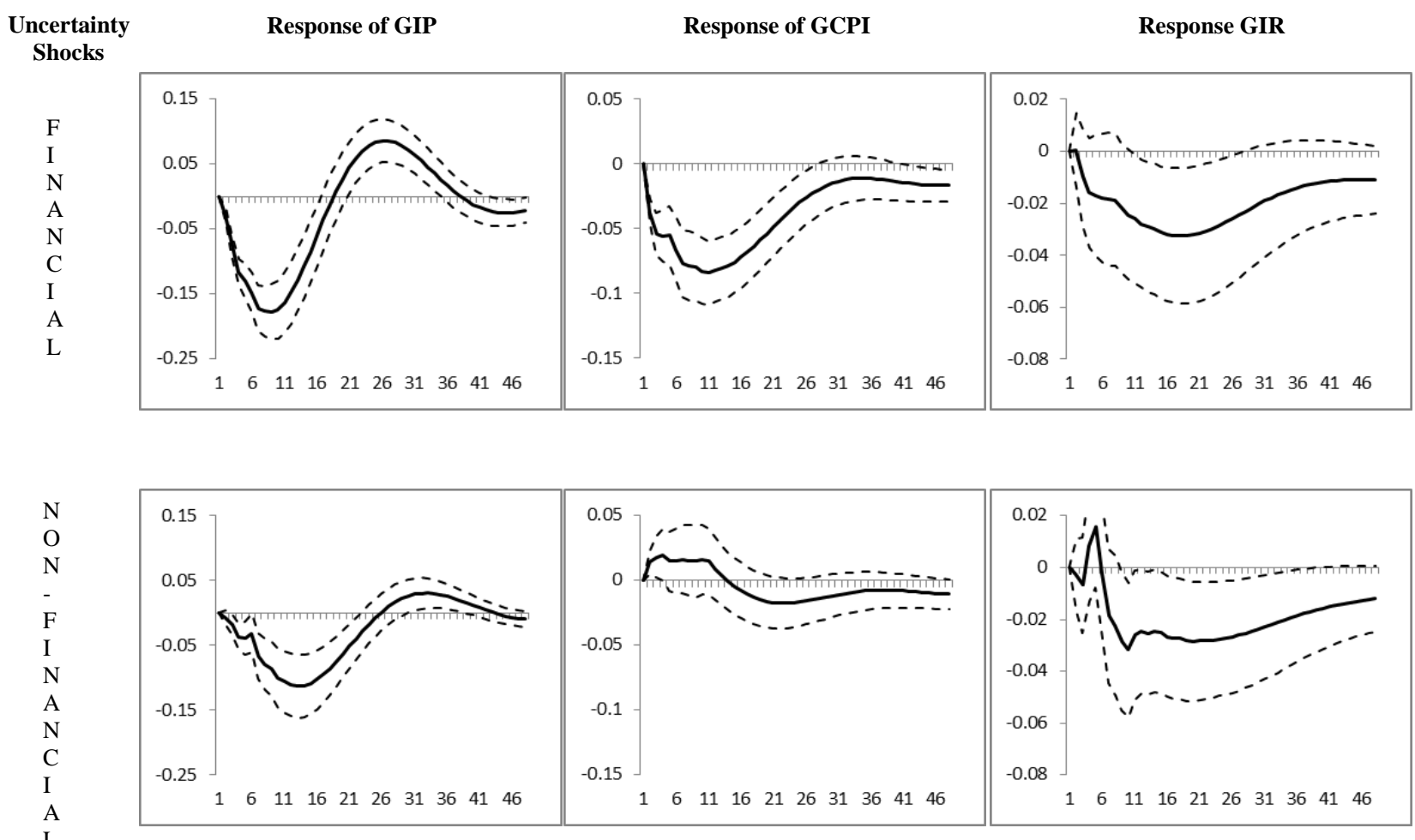

Note that to conserve space we only report results when 6 lags are specified in the FAVAR system. Results for 3 and 12 lags are available from the authors upon request. 


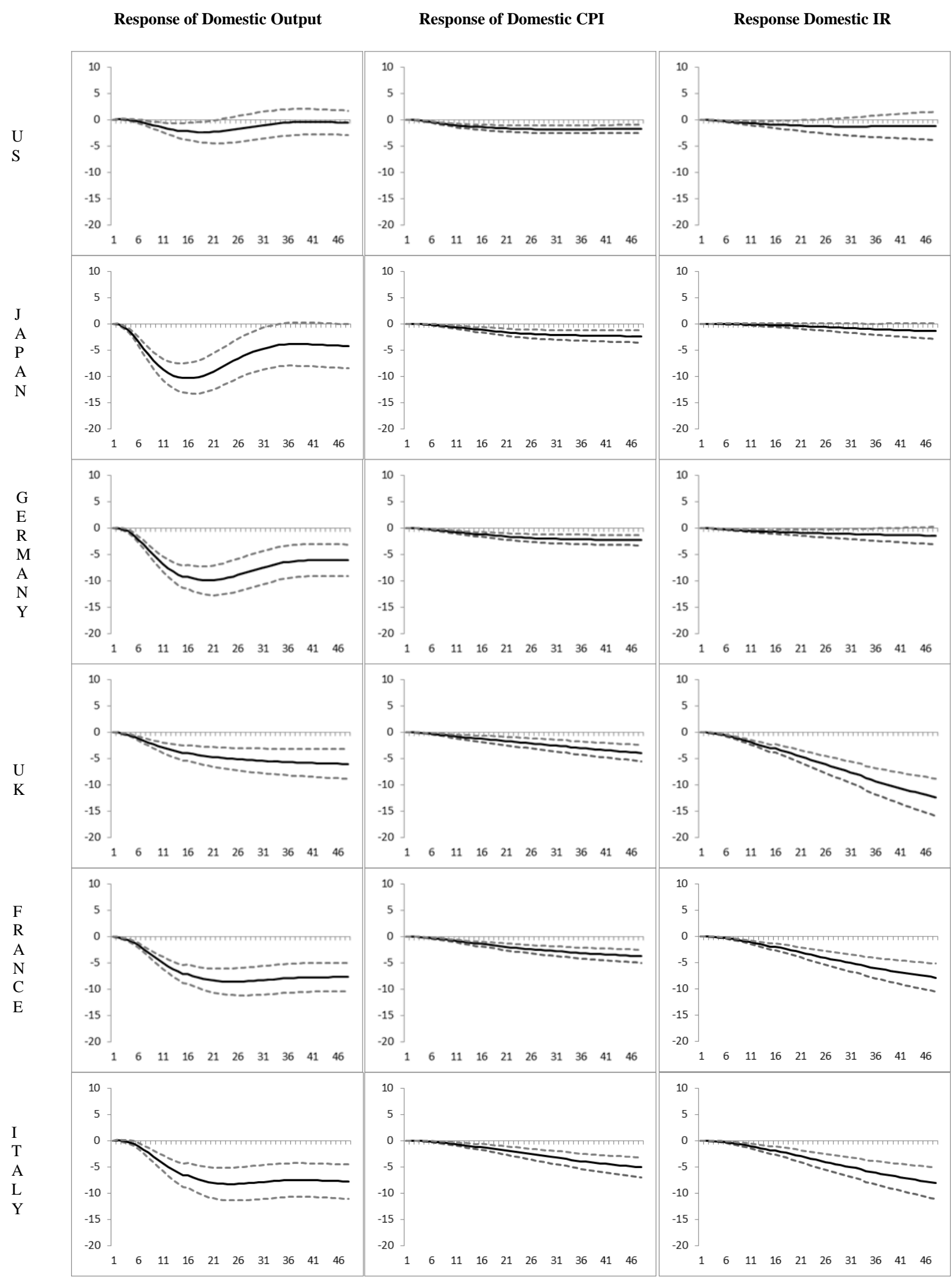

Figure 7a. Responses of large developed economies to global uncertainty shocks 
Notes: The dashed lines represent a one standard error confidence band around the estimates of the coefficients of the impulse response functions. The confidence bands are obtained using Monte Carlo integration as described by Sims (1980), where 5000 draws were used from the asymptotic distribution of the VAR coefficient.

\section{Figure 7b. Responses of large developing economies to global uncertainty shocks}

Response of Domestic Output

Response of Domestic CPI

Response Domestic IR
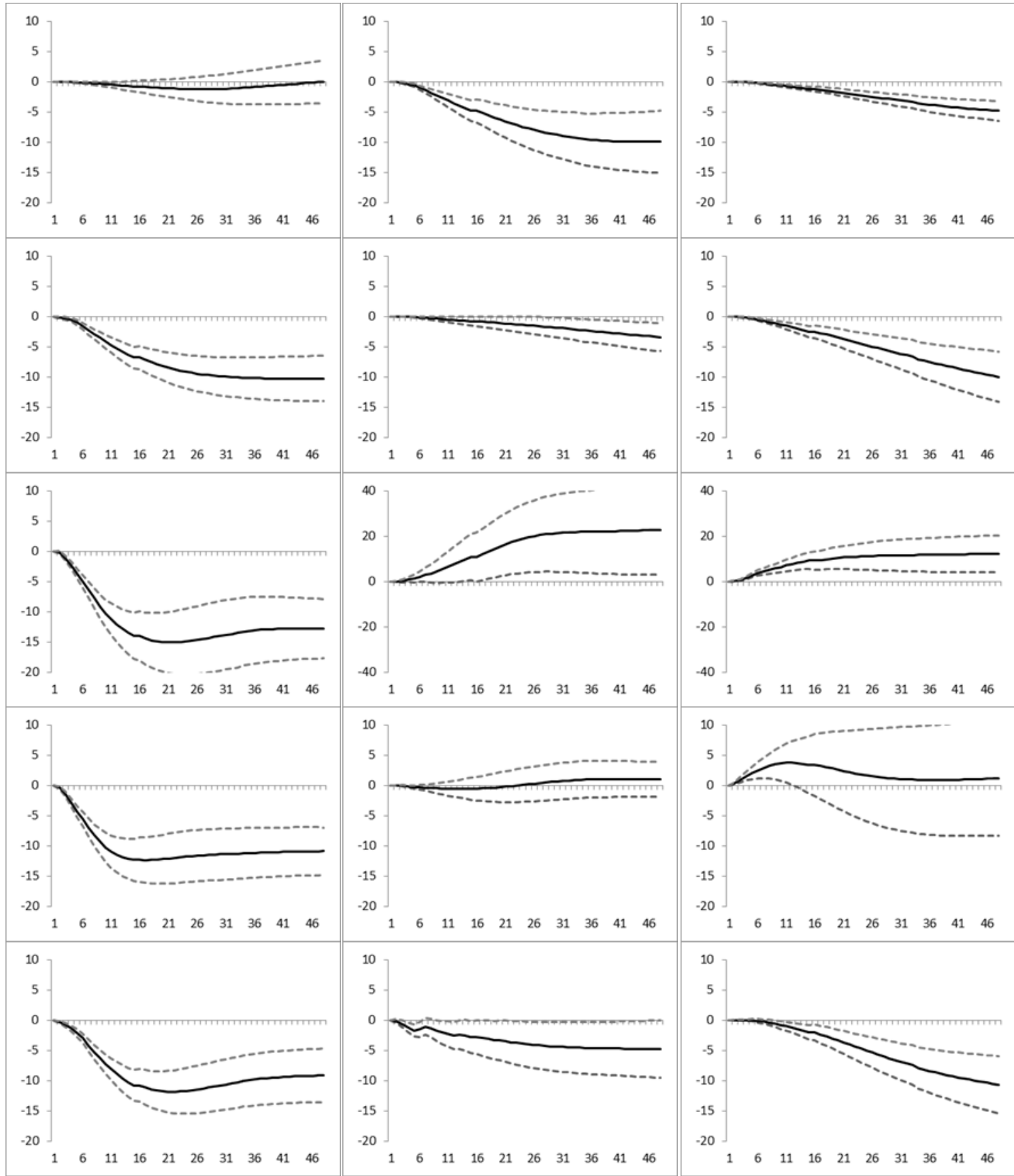

M
E
X
I
C
O
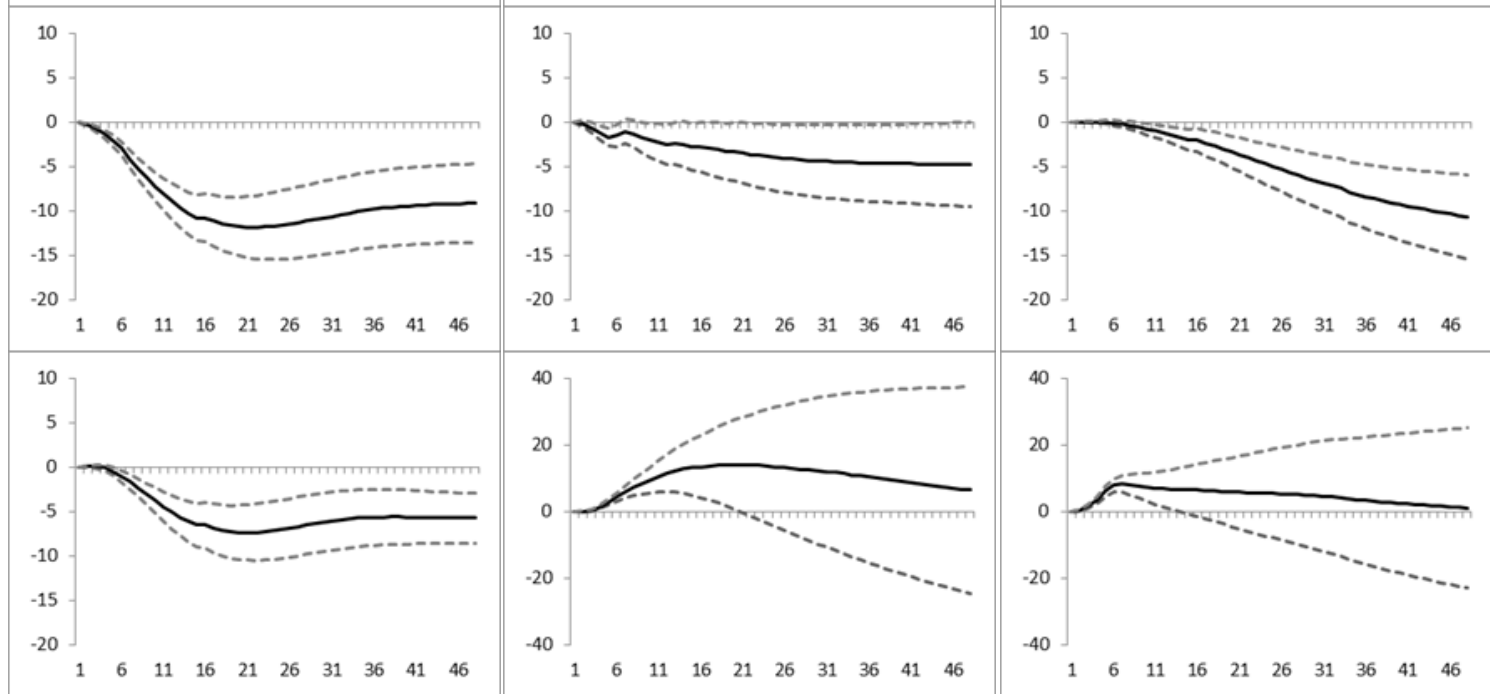
Notes: The dashed lines represent a one standard error confidence band around the estimates of the coefficients of the impulse response functions. The confidence bands are obtained using Monte Carlo integration as described by Sims (1980), where 5000 draws were used from the asymptotic distribution of the VAR coefficient. 
Appendix A: Data Appendix

Table A1. Data estimations for Equations 1 to 3, global uncertainty index. Stock market data from Datastream 5.1.

\begin{tabular}{|c|c|}
\hline Main stock market indicators by country & Period \\
\hline Australia: Standard \& Poor's/ASX 200 Index. & Jan 1981- Dec 2014 \\
\hline Brazil: BM\&F BOVESPA Index & Jan 1991- Dec 2014 \\
\hline Canada: Toronto Stock Exchange index & Jan 1981- Dec 2014 \\
\hline China: Shanghai Stock Exchange Composite Index & Dec 1990- Dec 2014 \\
\hline France: France CAC 40 Stock Market Index & Jan 1987- Dec 2014 \\
\hline Germany: Deutsche Boerse AG German Stock Index & Jan 1993- Dec 2014 \\
\hline India: NSE CNX 100 Index & Jan 2003- Dec 2014 \\
\hline Italy: FTSE MIB Index & Mar 2003- Dec 2014 \\
\hline Japan: NIKKEI 225 Stock Market Index & Jul 1988- Dec 2014 \\
\hline Mexico: Mexican Bolsa IPC Index & Dec 1991-Dec 2014 \\
\hline Russia: Russia MICEX Stock Market Index & Jan 1994- Dec 2014 \\
\hline South Korea: Korea Stock Exchange KOSPI Index & Jan 1990- Dec 2014 \\
\hline South Africa: South Africa FTSE/JSE Index & Jan 2001- Dec 2014 \\
\hline U.S: Standard \& Poor’s 500 index. & Jan 1981- Dec 2014 \\
\hline U.K: UK FTSE 100 Stock Market Index & Jan 1981- Dec 2014 \\
\hline
\end{tabular}

Table A2. Data estimations for Equations 4 to 7. Global databased from Database of Global Economic Indicators, Federal Reserve Bank of Dallas.

\footnotetext{
Name and description $\quad$ Period

IP for the U.S: is the total industrial production excluding construction Jan 1981- Dec 2014 for the U.S economy, index 2005 $=100$.

IP for advanced economies (ex. U.S): is the total industrial production Jan 1981- Dec 2014 excluding construction for the largest 31 advanced economies excluding the U.S, index 2005=100.

IP for emerging economies: is the total industrial production excluding Jan 1987- Dec 2014 construction for the largest 26 emerging economies, index 2005=100.

CPI for the U.S: is the headline consumer price index for the U.S, index Jan 1981- Dec 2014 $2005=100$.

CPI for advanced economies (ex. U.S): is the headline consumer price Jan 1981- Dec 2014 index for the largest 31 advanced economies excluding the U.S, index

$2005=100$.

CPI for emerging economies: is the headline consumer price index for Feb 1984- Dec 2014 the largest emerging economies excluding the U.S, index 2005=100.

Interest rate for the U.S: Federal funds target rate

Jan 1981- Dec 2014

Interest rate for advanced economies (ex. the U.S: Short term official July 1985- Dec 2014 policy rate (maturity 3 months or less) for the largest 31 advanced

economies excluding the U.S.

Interest rate for emerging economies (ex. the U.S): Short term official Jan 1981- Dec 2014 policy rate (maturity 3 months or less) for the largest 26 emerging economies excluding the U.S.

Notes: Global indicators for advanced and emerging are aggregated using U.S trade weights (for more detail see: Grossman, Mack and Martinez-Garcia). The largest economies according PPP-adjusted GDP shares from the IMF World Economic Outlook.
} 
Table A3. Chronology of the global financial crisis events

\begin{tabular}{ll}
\hline \multicolumn{1}{c}{ Period } & \multicolumn{1}{c}{ Event } \\
\hline September 13, 2007 & $\begin{array}{l}\text { Northern Rock has sought emergency funding from the Bank of } \\
\text { England in its capacity as "lender of last resort" } \\
\text { The UK government announces that struggling Northern Rock is to be } \\
\text { nationalised for a temporary period. }\end{array}$ \\
July 14, 2008 & $\begin{array}{l}\text { Financial authorities in U.S. step in to assist America's two largest } \\
\text { lenders, Fannie Mae and Freddie Mac, owners or guarantors of 5 } \\
\text { trillion worth of home loans. } \\
\text { September 15, 2008 }\end{array}$ \\
$\begin{array}{l}\text { Wall Street bank Lehman Brothers (U.S.) files for Chapter 11 } \\
\text { bankruptcy protection and another US bank, Merrill Lynch, is taken } \\
\text { over by the Bank of America. } \\
\text { The U.S. government took control of AIG. The U.S. The federal } \\
\text { government to take control of the company and guarantee to loan it up } \\
\text { to \$85 billion. }\end{array}$ \\
\hline
\end{tabular}

Table A4. Dummy variables for financial and non-financial shocks for Equation 9

\begin{tabular}{|c|c|c|c|}
\hline \multicolumn{2}{|c|}{ Global financial shocks above $1.65 \mathrm{SD}$} & \multicolumn{2}{|c|}{ Global non-financial shocks above 1.65 SD } \\
\hline Shock & Monthly dummy & Shock & Monthly dummy \\
\hline Black Monday & February to July 1987 & $\begin{array}{l}\text { September } 11 \\
\text { terrorist attack }\end{array}$ & $\begin{array}{l}\text { September to November } \\
2001\end{array}$ \\
\hline $\begin{array}{l}\text { Russian sovereign } \\
\text { debt crisis }\end{array}$ & May and June 1997 & Gulf War II & May to August 2002 \\
\hline $\begin{array}{l}\text { Global financial } \\
\text { crisis }\end{array}$ & $\begin{array}{l}\text { September } 2007 \text { to } \\
\text { November } 2008\end{array}$ & & \\
\hline
\end{tabular}


Table A5. Data estimations for Equations 10. Individual country estimations.

Variable: Industrial production, sa: the index cover production in mining, manufacturing and public utilities (electricity, gas and water), but excluding construction. The data is from Organization for Economic Co-operation and Development.

\begin{tabular}{llll}
\hline Country & Period & Country & Period \\
\hline Brazil & Jan 1981- Dec 2014 & Japan & Jan 1981- Dec 2014 \\
China & Mar 1990- Dec 2014 & Mexico & Jan 1981- Dec 2014 \\
France & Jan 1981- Dec 2014 & Russia & Jan 1993- Dec 2014 \\
Germany & Jan 1981- Dec 2014 & South Africa & Jan 1990- Dec 2014 \\
India & Jan 1994- Dec 2014 & U.S & Jan 1981- Dec 2014 \\
Italy & Jan 1981- Dec 2014 & U.K & Jan 1981- Dec 2014 \\
\hline
\end{tabular}

Variable: Consumer price index (all items), sa: is defined as the change in the prices of a basket of goods and services that are typically purchased by all households. The data is from Organization for Economic Co-operation and Development.

\begin{tabular}{llll}
\hline Country & Period & Country & Period \\
\hline Brazil & Jan 1981- Dec 2014 & Japan & Jan 1981- Dec 2014 \\
China & Jan 1994- Dec 2014 & Mexico & Jan 1981- Dec 2014 \\
France & Jan 1981- Dec 2014 & Russia & Jan 1997- Dec 2014 \\
Germany & Jan 1981- Dec 2014 & South Africa & Jan 1981- Dec 2014 \\
India & Jan 1981- Dec 2014 & U.S & Jan 1981- Dec 2014 \\
Italy & Jan 1981- Dec 2014 & U.K & Jan 1981- Dec 2014 \\
\hline
\end{tabular}

\begin{tabular}{llll}
\hline Variable: Official interest rate: & & \\
\hline Country & Period & Country & Period \\
\hline Brazil & Oct 1996- Dec 2014 & Japan & Jan 1981- Dec 2014 \\
China & Mar 1990- Dec 2014 & Mexico & Jan 1981- Dec 2014 \\
France & Jan 1981- Dec 2014 & Russia & Jan 1993- Dec 2014 \\
Germany & Jan 1981- Dec 2014 & South Africa & Jan 1981- Dec 2014 \\
India & Jan 1981- Dec 2014 & U.S & Jan 1981- Dec 2014 \\
Italy & Jan 1981- Dec 2014 & U.K & Jan 1981- Dec 2014 \\
\hline
\end{tabular}




\section{Supplementary Material 1: The Bayesian Approach}

The VAR model in Equation (4) is conventionally estimated by ordinary least square (OLS) or maximum likelihood estimator (MLE). For the economic application of the VAR model, accurate estimation of finite sample distributions of $(A, \Sigma)$ is important (such as the approximation of nonlinear impulse-response functions). However, the VAR model includes $(p+1) m$ unknown parameters for the vector of regression coefficient and $m \times m$ unknown elements of the variance-covariance matrix. In the OLS/MLE estimation, the number of unknown parameters are relatively large relative to the data at hand. To assess the robustness, we utilize the Bayesian analysis to capture the uncertainty in the parameter estimation and in the valuation for the precision of inference and the reliability of prediction.

A Bayesian version of the FAVAR model in Equation (4) is now described. For compactness we may rewrite the model in Equation (4) as

$$
Y=X A+E,(\mathrm{~A} .1)
$$

or

$$
y=\left(I_{m} \otimes X\right) \theta+e,\left(\text { A. } 1^{\prime}\right)
$$

where $\mathrm{Y}$ and $\mathrm{E}$ are $T \times m$ matrices, $X=\left(x_{1}, \ldots, x_{t}\right)^{\prime}$ is a $T \times(m p+1)$ matrix for $x=\left(1, y_{t-1}^{\prime}, \ldots, y_{t-q}^{\prime}\right), I_{m}$ is the identify matrix of dimension $m, \theta=\operatorname{vec}(A)$, and $e_{t} \sim N\left(0, \Sigma_{\epsilon} \otimes I_{T}\right)$. The likelihood function is:

$$
l\left(\theta, \Sigma_{\epsilon}\right) \propto\left|\Sigma_{\epsilon} \otimes I_{T}\right|^{-0.5} \exp \left\{-0.5\left(y-\left(I_{m} \otimes X\right) \theta\right)^{\prime\left(\Sigma_{\epsilon} \otimes I_{T}\right)^{-1}}\left(y-\left(I_{m} \otimes X\right) \theta\right)\right\} . \text { (A.2) }
$$

To derive the posterior moments in the Bayesian analysis, let assume that $\Sigma_{\epsilon}$ is known and a multivariate normal prior for $\theta$ is

$$
\Pi(\theta) \propto\left|\mathrm{V}_{o}\right|^{-0.5} \exp \left\{-0.5\left(\theta-\theta_{0}\right)^{\prime} V_{0}^{-1}\left(\theta-\theta_{0}\right)\right\}, \text { (A.3) }
$$

where $\theta_{0}$ is the prior mean and $\mathrm{V}_{o}$ is the prior variance-covariance matrix. When we combine this prior with the likelihood function, the posterior density can be written as

$$
\Pi(\theta \mid y)=\exp \left\{-0.5\left(\left(V_{0}^{-0.5}\left(\theta-\theta_{0}\right)^{\prime} V_{0}^{-0.5}\left(\theta-\theta_{0}\right)\right.\right.\right.
$$




$$
\left.\left.+\left\{\left(\Sigma_{\epsilon}^{-0.5} \otimes I_{T}\right)-\left(\Sigma_{\epsilon}^{-0.5} \otimes X\right) \theta\right\}^{\prime}\left\{\left(\Sigma_{\epsilon}^{-0.5} \otimes I_{T}\right) y-\left(\Sigma_{\epsilon}^{-0.5} \otimes X\right) \theta\right\}\right)\right\}, \text { (A.4) }
$$

a multivariate normal probability density function. Define

$$
\begin{gathered}
\omega \equiv\left[\frac{V_{0}^{-0.5} \theta_{0}}{\left(\Sigma_{\epsilon}^{-0.5} \otimes I_{T}\right) y}\right], \\
W \equiv\left[\frac{V_{0}^{-0.5}}{\left(\Sigma_{\epsilon}^{-0.5} \otimes X\right)}\right] .
\end{gathered}
$$

The posterior density is

$$
\begin{array}{r}
\Pi(\theta \mid y) \propto \exp \left\{-0.5\left((\omega-W \theta)^{\prime}(\omega-W \theta)\right\} \propto\right. \\
\exp \left\{-0.5(\theta-\bar{\theta})^{\prime} W^{\prime} W(\theta-\bar{\theta})+(\omega-W \bar{\theta})^{\prime}(\omega-W \bar{\theta})\right\},
\end{array}
$$

where the posterior mean $\bar{\theta}$ is:

$$
\bar{\theta}=\left(W^{\prime} W\right)^{-1} W^{\prime} \omega=\left[V_{0}^{-1}+\left(\Sigma_{\epsilon}^{-1} \otimes X^{\prime} X\right)\right]^{-1}\left[V_{0}^{-1} \theta_{0}+\left(\Sigma_{\epsilon}^{-1} \otimes X\right)^{\prime} y\right] . \text { (A.6) }
$$

We utilize a Minnesota prior that involves setting the elements of $\theta_{0}$ to be zero to ensure shrinkage of the VAR coefficients toward zero and reduce the over-fitting risk. It assumes the prior covariance matrix $\mathrm{V}_{o}$ to be diagonal, in the sense that own lags of endogenous variables are more likely to be important predictors than lags of other variables. The error variance-covariance matrix is the standard OLS estimate of the error terms $\widehat{\Sigma_{\epsilon}}=S / T$.

Alternatively, we estimate the FABVAR model using two different non-informative priors, in that the Minnesota prior ignores any uncertainty in the elements of error variancecovariance matrix $\Sigma_{\epsilon}$. The first is the natural conjugate prior that treats $\Sigma_{\epsilon}$ as an unknown parameter, $\Sigma_{\epsilon}^{-1} \sim W\left(S^{-1}, v\right)$, where $S$ is the prior hyper-parameters. Here we choose small degree of freedom parameters, $v=m(m-1)+1$ and $S=0.01 \times m(m-1) \times I_{m(m-1)}$, in order to put a small weight on the priors that makes the priors to contain small amount of information relative to the sample. The second is the Sims-Zha normal-Wishart prior for $\Sigma_{\epsilon}$ using the fictitious observations (Sim and Zha (2008)), for example $\widehat{\Sigma_{\epsilon}}=\left(X^{\prime} X\right)^{-1}$. 
Figure B1. FABVAR model: Response of global industrial production, global inflation and global interest rate to global uncertainty shocks

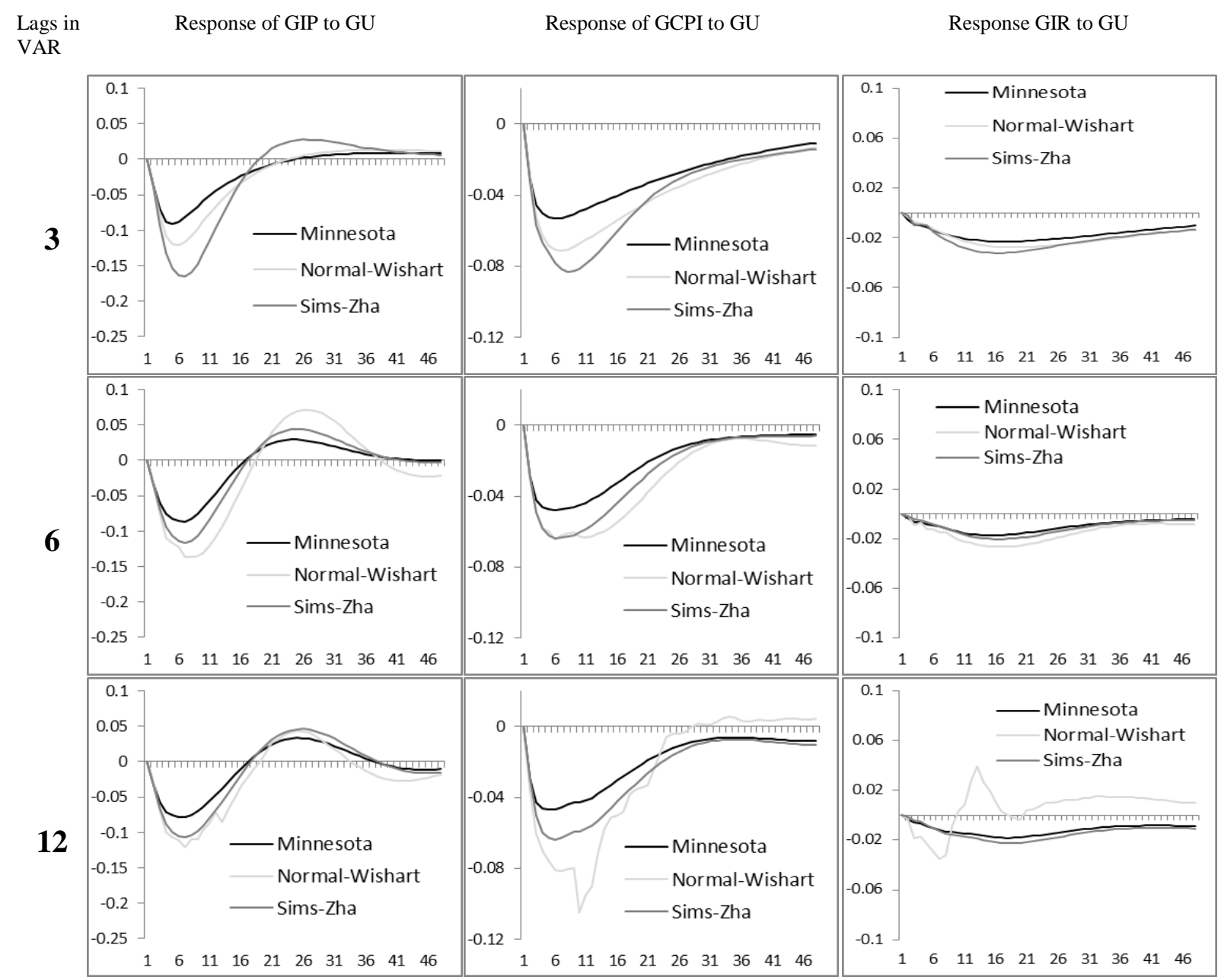




\section{Figure B2. FABVAR model: Responses of global variables to U.S and global uncertainty shocks}

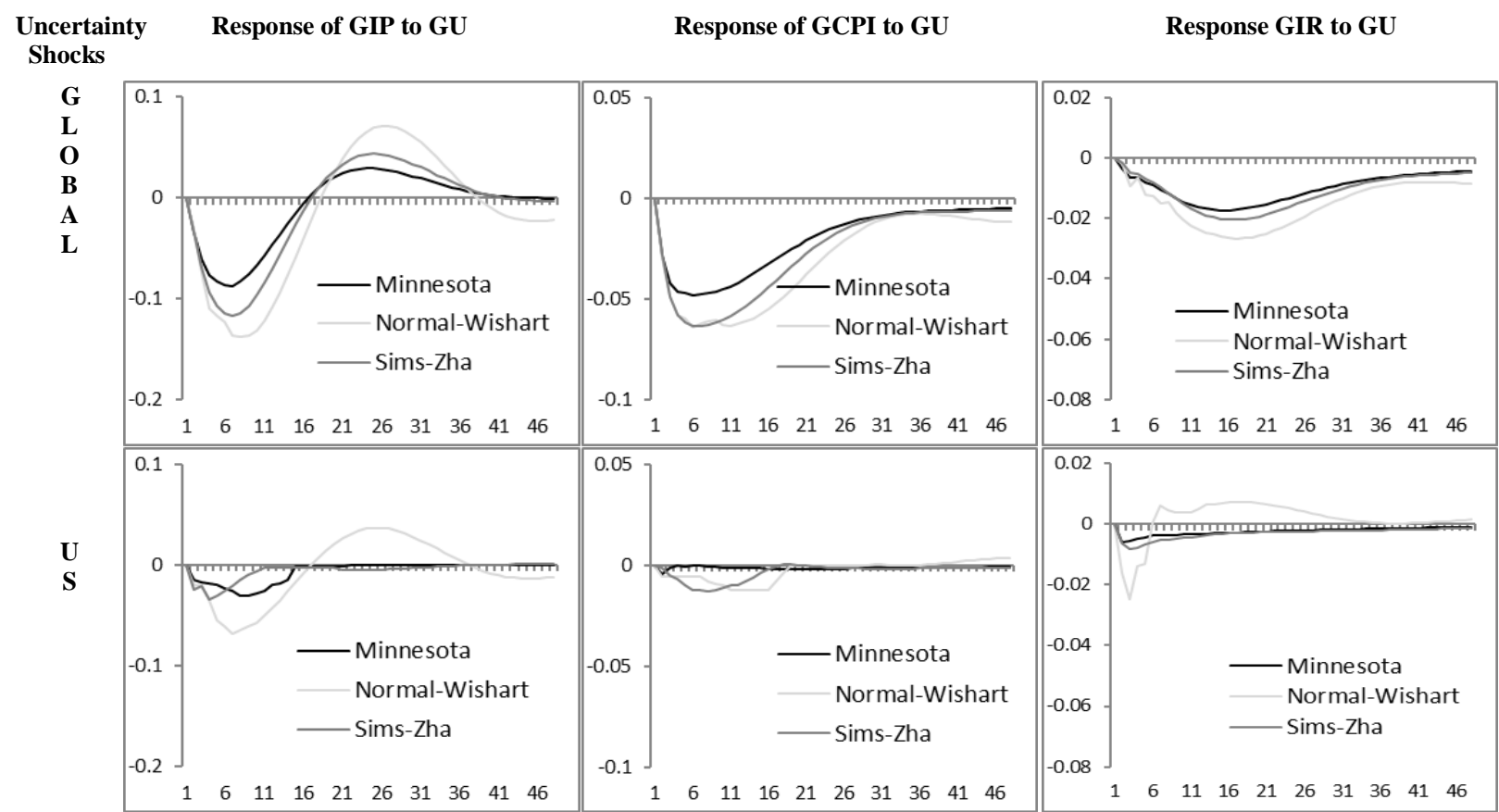

Notes: To conserve space we only report results when 6 lags are specified in the FABVAR system. Results for 3 and 12 lags are available from the authors upon request.

\section{Figure B3. FABVAR model: Responses of global variables to financial and non- financial uncertainty shocks}

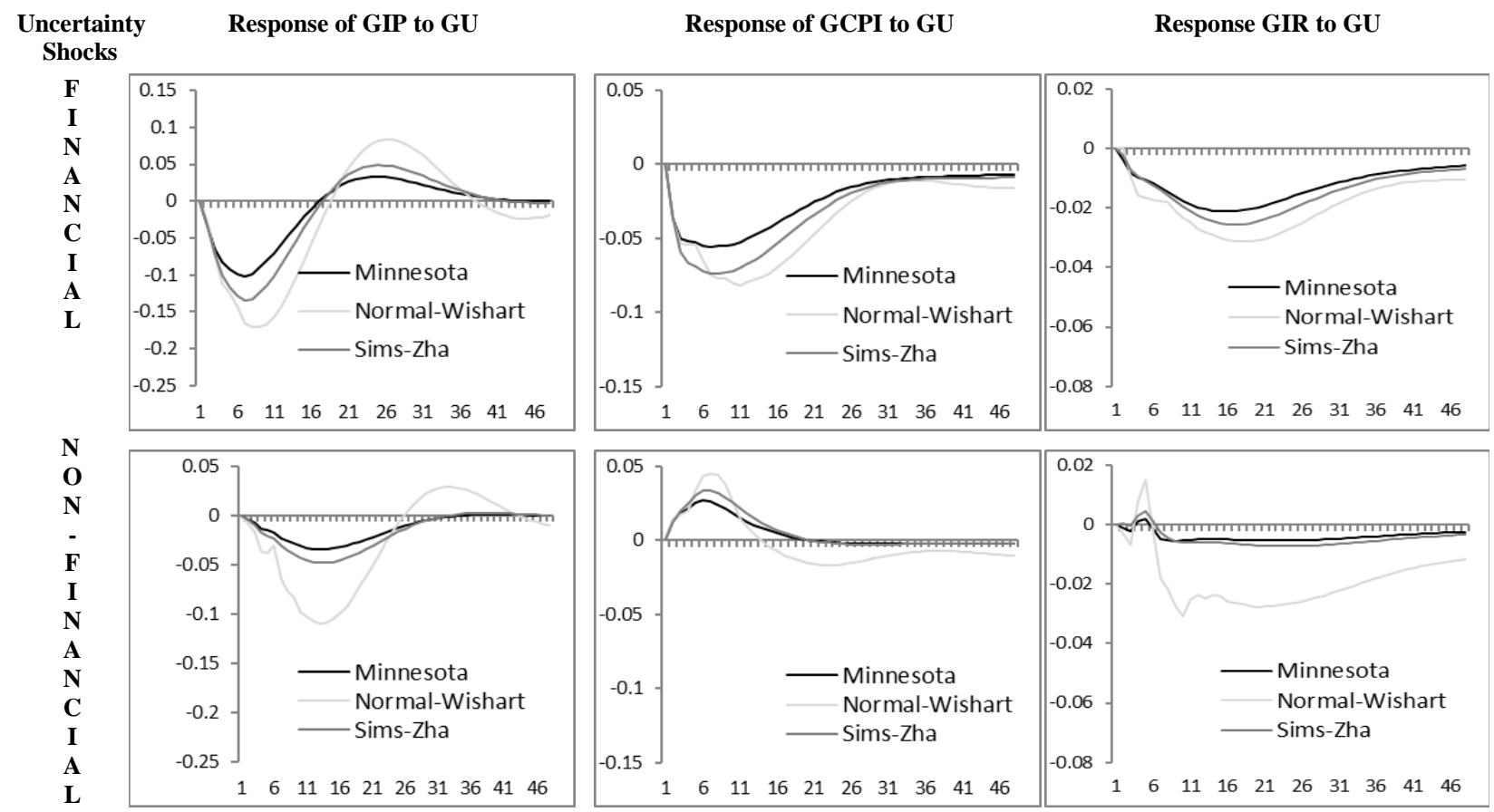

Notes: To conserve space we only report results when 6 lags are specified in the FABVAR system. Results for 3 and 12 lags are available from the authors upon request. 
Figure B4. FABVAR: Responses of large developed economies to global uncertainty shocks

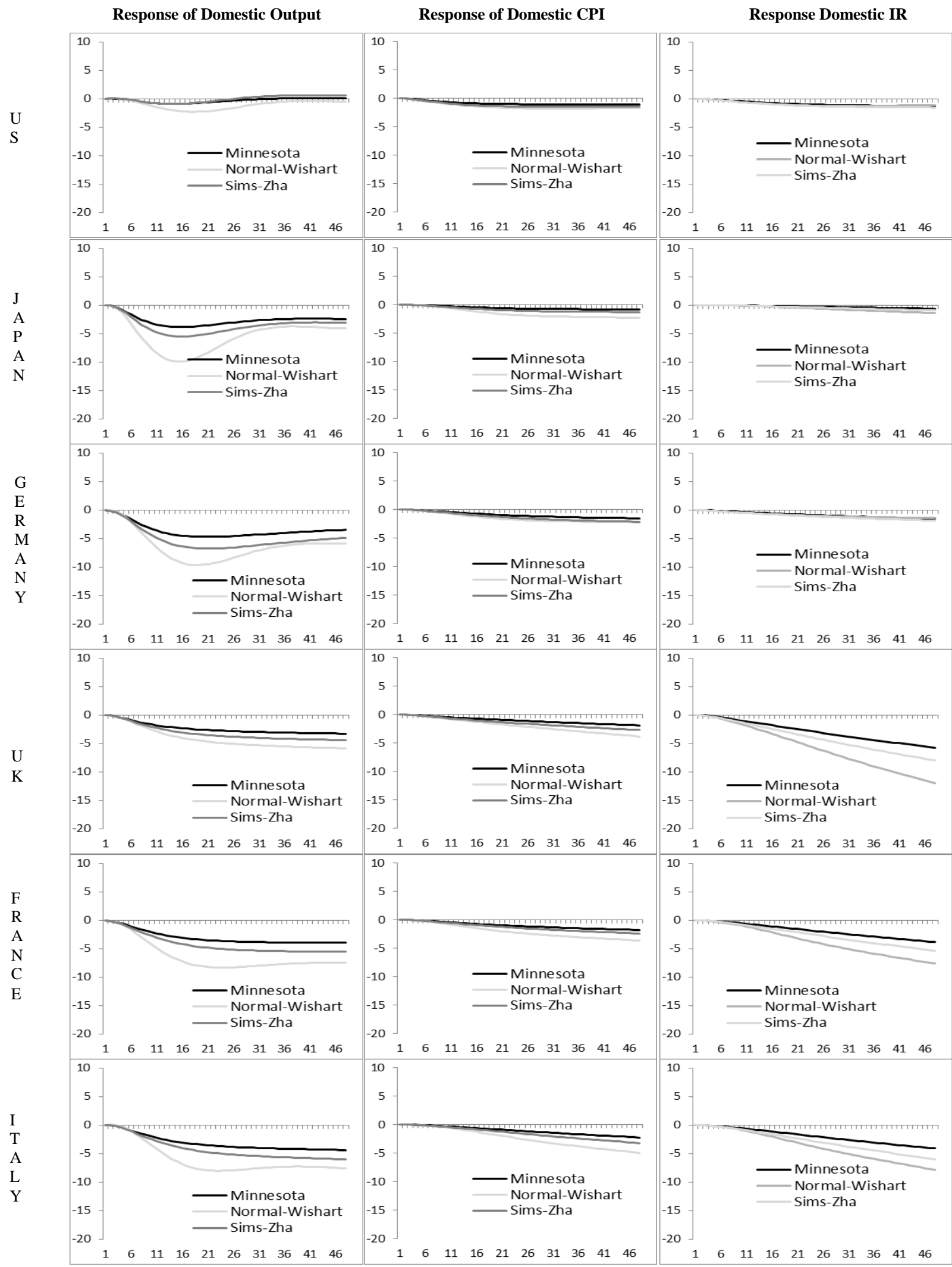


Figure B5. FABVAR: Responses of large developing economies to global uncertainty shocks

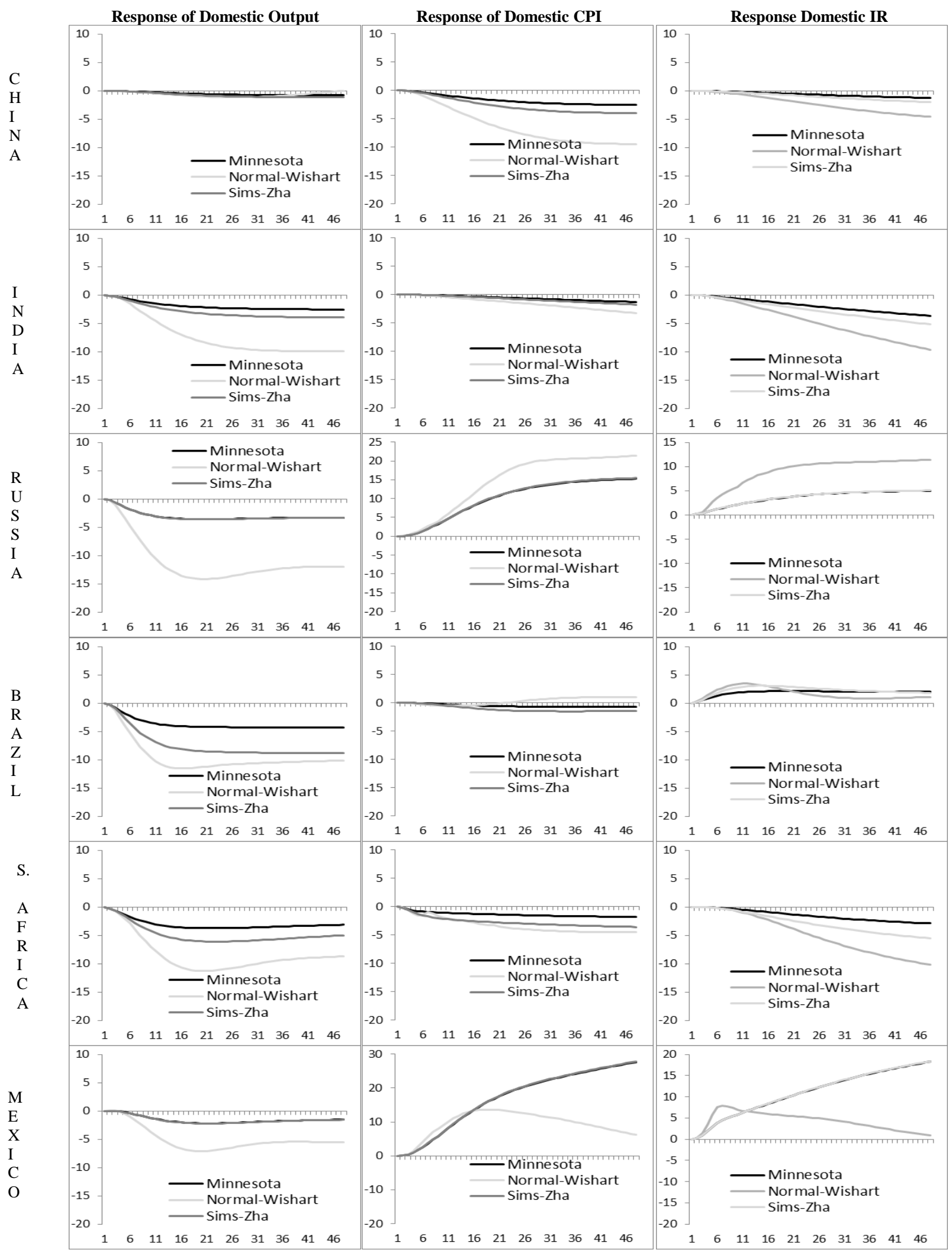




\section{Discussion}

\section{The effects of global uncertainty shocks on the economy in the FABVAR model}

Figure B1 shows the impact of one standard deviation global uncertainty shocks on global industrial production growth, global CPI inflation and global interest rate for the FABVAR model, with vector of endogenous variables $y_{t}=\left(\Delta\left(G I P_{t}\right)\right.$, $\left.\Delta\left(G C P I_{t}\right), G I R_{t}, G U_{t}\right)$. The model is estimated with 3, 6 and 12 lags, as indicated on the left hand side of Figure B1. Each column in Figure B1 shows the response of global interest rate, global CPI inflation and global industrial production growth to global uncertainty shocks. The timing and magnitude of the responses to a one-time global uncertainty shock in the economy in Figure B1 are very similar to the results in Figure 4 from the FAVAR model.

In brief, global uncertainty shocks are accompany a quick decline in global industrial production growth that is most severe after 4 to 8 months. Global uncertainty shocks are associated with a quick and sharp decline in global CPI reaching the greatest levels of decline after 6 to 12 months, depending on the number of lags and the prior adopted. Global uncertainty shocks are associated with a decline in global interest rate that persists, with the greatest decline in the global interest rate observed over 16 to 20 months. The only exception to the latter results for the impact of global uncertainty on the global interest rate is for the FABVAR model with Sims-Zha prior, for which case the decline in interest rate is greatest after 7 or 8 months and is reversed after 10 months.

\section{Effects of global uncertainty and U.S. uncertainty shocks in the FABVAR model}

The effects of global uncertainty and U.S. uncertainty shocks on the variables in the FABVAR model are now presented. The vector of endogenous variables is a $(m=5) \times 1$ given by $y_{t}=\left(\Delta\left(G I P_{t}\right), \Delta\left(G C P I_{t}\right), G I R_{t}, U S U_{t}, G U_{t}\right)$. The responses of global industrial production, CPI and interest rate to global uncertainty shocks and to U.S. uncertainty shocks are shown in the first and second rows of Figure B2 respectively. 
The results for the responses to global uncertainty (after controlling for U.S. uncertainty) are well defined for all priors and very similar to the results obtained from the FAVAR model shown in Figure 5. A one-standard deviation shock to global uncertainty is associated with decreases in global industrial production over 1 to 16 months, persistent reductions in global CPI with the deepest decline over 3 to 12 months (depending on prior), and continual reductions in the global interest rate with the most decline over 12 to 16 months (depending on prior).

The results for the responses to U.S. uncertainty after controlling for global uncertainty are also similar to the results obtained from the FAVAR model shown in Figure 5, in that they are small and ill defined. The results from the FABVAR model reinforce the finding that global uncertainty shocks dominate U.S. uncertainty shocks in terms of influence on the global economy. The responses of global output, CPI and interest rate to U.S uncertainty shocks are much smaller in absolute value than the negative responses of global output, CPI and interest rate to global uncertainty shocks.

\section{Financial vs. non-financial uncertainty shock in the FABVAR model}

The impacts of financial and non-financial uncertainty shocks on the global macroeconomic variables estimated from the FABVAR model are presented in Figure B3. The vector of endogenous variables is $y_{t}=\left(\Delta\left(G I P_{t}\right), \Delta\left(G C P I_{t}\right), G I R_{t}, F D_{t} * G U_{t}, D N F_{t} *\right.$ $G U_{t}$ ), where the fifth and sixth variables are the global financial uncertainty and global nonfinancial uncertainty components of global uncertainty. In the first and second rows of Figure B3 the impact of financial and non-financial uncertainty shocks on global industrial production, CPI and interest rate are shown. Results for the impacts of global financial and non-financial uncertainty shocks are similar to those reported for the FAVAR model earlier (in Figure 6). 
The financial uncertainty shocks have a much larger impact in absolute value than the non-financial shocks in reducing global industrial production. The differences between the responses of global CPI to global financial and non-financial uncertainty shocks persist in the FABVAR estimation. Financial uncertainty shocks have a negative effect on global CPI and non-financial shocks have a positive effect. Decline in global interest is associated with both global financial and non-financial uncertainty shocks, but now the effect of the financial shock is persistently negative.

\section{Effects of global uncertainty on domestic economies in the FABVAR model.}

Results for the impulse responses of domestic output, domestic inflation and domestic interest rate for the largest economies from the FABVAR model appear in Figures B4 and B5 for developed or developing economy respectively. The endogenous variables in the FABVAR model estimated are given by $y_{t}=\left(\Delta\left(D I P_{t}\right), \Delta\left(D C P I_{t}\right), D I R_{t}, D U_{t}, G U_{t}\right)$, where the first four variables are output, CPI, interest rate and uncertainty for a large developed or developing economy and the last variable is global uncertainty. Results are again similar to those reported for the FAVAR model.

In Figures B4 and B5 the decline in the outputs of the US and of China are more muted in response to increased global uncertainty than are the outputs of the other countries. For most countries, the responses of domestic inflation and the official interest to positive shocks to global uncertainty are negative and consistent with the result for the negative effect of shocks to global uncertainty on domestic output. The exceptions are again Brazil, Mexico and Russia. For Brazil, Mexico and Russia, an increase in global uncertainty is associated with increases the official interest rate, and Mexico and Russia an increase in global uncertainty is associated with increases the official interest. 
